\title{
The Patent Paradox Revisited: An Empirical Study of Patenting in the US Semiconductor Industry, 1979-95
}

\author{
Bronwyn H. Hall* and Rosemarie Ham Ziedonis**
}

May 2000

\begin{abstract}
This paper examines the patenting behavior of firms in an industry characterized by rapid technological change and cumulative innovation. Recent survey evidence suggests that semiconductor firms do not rely heavily on patents to appropriate the returns to $R \& D$, despite the strengthening of US patent rights in the early 1980s. Yet the propensity of semiconductor firms to patent has risen dramatically over the same period. This paper explores this apparent paradox by conducting interviews with industry representatives and analyzing the patenting behavior of approximately 100 US semiconductor firms during a period that spans the "pro-patent" shift in the US legal environment. The results suggest that the strengthening of US patent rights spawned "patent portfolio races" among capital-intensive firms, but also may have facilitated entry by specialized design firms during this period.
\end{abstract}

JEL Codes: O34, O32, L63

Keywords: Patents, IPR, semiconductor industry, cumulative R\&D

* Department of Economics, University of California, Berkeley; Nuffield College, Oxford University; National Bureau of Economic Research; Institute for Fiscal Studies, London.

**Wharton School of Business, University of Pennsylvania.

An earlier version of this paper was prepared for the January 1999 NBER Conference on "The Patent System and Innovation," sponsored by the Alfred P. Sloan Foundation. The Alfred P. Sloan Foundation's Competitive Semiconductor Manufacturing Grant to UC Berkeley and the US Air Force Office of Scientific Research provided additional support for this study through doctoral research grants to Ziedonis. We extend special thanks to the managers and intellectual property attorneys who participated in our study and shared their time and insights with us. We also thank Jerry Karls of Integrated Circuit Engineering, Inc. for sharing industry data and Jeff Macher of UC Berkeley's Haas School of Business for facilitating and participating in several of our interviews. Finally, we gratefully acknowledge the helpful comments and suggestions we received from two anonymous reviewers, Melissa Appleyard, Clair Brown, Wes Cohen, David Hodges, Adam Jaffe, Jenny Lanjouw, Josh Lerner, Kristina Lybecker, Rob Merges, David Mowery, Rob Porter (the editor), Cecil Quillen, Dennis Yao, Arvids Ziedonis and participants in the Berkeley Innovation Seminar, the NBER "Patent System and Innovation" Conference, and the STEP Board Conference on Intellectual Property Rights, Washington D.C., February 2-3, 2000.

\section{Introduction}




\section{Introduction}

In the early 1980s, important changes in the US legal environment ushered in an era characterized by strong patent rights. Most notable among these changes was the 1982 formation of a centralized appellate court, the Court of Appeals for the Federal Circuit (CAFC). Although the CAFC is widely credited with unifying and strengthening the judicial treatment of patent rights in the United States, the effects of the "pro-patent" court on the innovative activities of firms remain unclear. For example, survey evidence suggests that firms in most industries have not increased their reliance on patents for appropriating the returns to R\&D over the decade of the 1980s (Cohen, Nelson, and Walsh 2000). Yet this period coincides with an unprecedented surge in patenting in the United States unaccounted for by increases in R\&D spending alone (Kortum and Lerner 1998). If firms in most industries do not rely heavily on patents to profit from innovation, then why are they patenting so aggressively?

This paper re-visits this "patent paradox" in the semiconductor industry, where the gap between the relative ineffectiveness of patents (as reported in surveys) and their widespread use is particularly striking. In two surveys on appropriability conducted in 1983 and 1994, (the "Yale" and "Carnegie Mellon" surveys, respectively), R\&D managers in semiconductors consistently reported that patents were among the least effective mechanisms for appropriating returns to R\&D investments (Levin et al. 1987; Cohen et al. 2000). ${ }^{1}$ Driven by a rapid pace of technological change and short product life cycles, semiconductor firms tend to rely more heavily on lead time, secrecy, and manufacturing or design capabilities than patents to recoup investments in R\&D. Nonetheless, the number of semiconductor-related patents issued in the United States has risen sharply since the early 1980 s, exceeding the overall increase examined by Kortum and Lerner (1998). ${ }^{2}$ Even more important, the propensity of semiconductor firms to patent has also risen during this period. As shown in Figure 1, we find that patenting per million real R\&D dollars in the semiconductor industry has doubled between 1982 and 1992, from about 0.3 to 0.6. ${ }^{3}$ During the same period, the patent yield for manufacturing as a whole was fairly stagnant and that for pharmaceuticals actually declined.

\footnotetext{
${ }^{1}$ The 1994 Carnegie Mellon Survey on Industrial R\&D in the U.S. Manufacturing Sector (Cohen et al. 2000) updated and extended the influential "Yale" survey conducted in 1983 (Levin et al. 1987). Respondents in both surveys were R\&D lab managers in a variety of "focus industries." Both surveys found that R\&D managers in only a handful of industries, including pharmaceuticals, chemicals, and (more recently) biotechnology and medical devices, considered patents to be an effective mechanism by which to appropriate the returns to R\&D. These results echo the findings of Scherer et al. (1959), Taylor and Silberston (1973) and Mansfield (1986). As discussed below, the Carnegie Mellon survey extends upon the Yale survey by asking questions on why firms seek patent protection.

${ }_{2}^{2}$ The number of US patents issued in a narrowly-defined set of semiconductor patent classes more than doubled between 1981 and 1984, while the number of US patents issued in all US patent classes rose by only 50 percent during this period (USPTO 1995).
} 
The semiconductor industry also provides an excellent setting within which to examine the effects of stronger patent rights on firms engaged in rapidly advancing, "cumulative" technologies (Scotchmer 1991; Merges and Nelson 1990). Much like multimedia or computer firms, semiconductor firms often require access to a "thicket" of intellectual property rights in order to advance the technology or to legally produce or sell their products. Given the rapid pace of technological change in this industry, however, any new product or process is likely to overlap with technologies developed, either in parallel or in the past, by an array of external parties (Grindley and Teece 1997). Despite significant advancements in the theoretical literature on the importance of strong patent rights on inducing investments in $R \& D$ when innovation is cumulative (e.g., Scotchmer 1996; O’Donoghue et al 1998), there remains little systematic evidence on how a shift toward stronger patent rights affects the innovative activities of firms in the context of rapidly changing, cumulative technologies. ${ }^{4}$ Our study casts new empirical light on this issue by examining the patenting behavior of semiconductor firms during a period that spans the "pro-patent" shift in the US legal environment.

In order to illuminate the factors underpinning the surge in patenting in this industry and the effects, if any, of stronger US patent rights on the innovative activities of semiconductor firms, we employed a combination of qualitative and quantitative research methods. First, we conducted interviews with intellectual property managers and executives from several US semiconductor firms - including manufacturers and specialized design firms. Although previous studies have explored the motives for patenting in this industry, ${ }^{5}$ we sought additional insights on whether the increased patenting per R\&D dollar we find in this industry appears to be related to the strengthening of US patent rights in the 1980s or whether it seems to be driven by unrelated technological or managerial factors (an important alternative hypothesis). These interviews also enabled us to investigate the use of patents by semiconductor design firms, which specialize in chip design and contract out the manufacture of their products to other firms. Many of these firms entered the industry during the period associated with strong patent rights, but the importance of patent rights to these firms was unclear.

\footnotetext{
${ }^{3}$ The numbers in Figure 1 were compiled from several sources described in Section 4 below.

${ }^{4}$ The most extensive treatment of these issues (Merges and Nelson 1990) relies on historical records to trace the effects of conferring broad patent rights to inventors engaged in so-called "cumulative systems" technologies, such as electronics, aircraft or automobiles. In settings where technological advance involves a diverse range of entities involved in the "systems" architecture, the authors find that the issuance of broad, overlapping patents may lead to mushrooming transactions costs and therefore slow the pace of innovation. See also discussion in Mazzoleni and Nelson (1998).

${ }^{5}$ For example, see Tilton (1971), Taylor and Silberston (1973), von Hippel (1988) and, more recently, Grindley and Teece (1997) and Cohen et al. (2000).
} 
Our quantitative analysis is based on a much larger sample of approximately 100 publicly traded, US firms whose principal line of business is semiconductors and related devices (SIC3674) and whose R\&D expenditures are therefore primarily directed towards semiconductorrelated areas. ${ }^{6}$ After compiling a detailed database of these firms' patent portfolios from 1975 to 1998, we match these data with financial variables from Compustat (e.g., R\&D and sales) that are known determinants of patenting in general ${ }^{7}$ and that capture additional variables identified in our interviews. This methodology enables us to advance upon existing studies by constructing reliable estimates of the patent propensities of individual firms during this twenty-year period while keeping the broad technological area constant across firms. ${ }^{8}$ Thus we are able to determine whether the upsurge in patenting simply represents changes in the mix of firms in the industry over time (i.e., the effects of entry and exit), changes in the economic behavior of firms, or both. An unfortunate weakness of this approach is the exclusion from our analysis of large US "systems" manufacturers (e.g., IBM, AT\&T or Motorola) and non-US firms (e.g., Toshiba, Samsung or Siemens) that are important patent owners and users of semiconductor technologies. Because corporate R\&D spending is reported for the entire portfolio of a firm's R\&D activities, it is not possible to isolate the share of $R \& D$ expenditures directed toward semiconductor technologies for these diversified firms.

Our central hypothesis is that the increase in the patent propensities of semiconductor firms is driven by the "pro-patent" shift in the US legal environment in the 1980s. We distinguish, however, between two potential effects of strengthened patent rights on the intensified patenting we observe in this industry. First, the enhanced enforcement environment could induce more aggressive patenting by firms most vulnerable to "hold up" in the new patent regime. We label this our "strategic response" hypothesis. Because the costs and risks associated with being "held up" by external patent owners appear to be especially salient for firms with large sunk costs in complex manufacturing facilities, we test this hypothesis by examining the patenting behavior of large-scale manufacturers and whether it has changed in the period of strong US patent rights. Second, a shift toward stronger patent rights could facilitate vertical

\footnotetext{
${ }^{6}$ As discussed in Section 4, we expanded our sample of firms specializing in semiconductor chip design by using industry data provided to us by Integrated Circuits Engineering, Inc.

${ }^{7}$ See Hausman, Hall, and Griliches (1984) and Hall, Griliches, and Hausman (1986), also discussed in Section 4.

${ }^{8}$ In contrast, Kortum and Lerner (1998) examine the increase in patenting activity in particular classes (e.g., software and biotechnology) and then look at aggregate trends in R\&D intensity across the US and other national economies. As such, they are unable to determine whether the increased patenting activity in certain areas is simply due to a simultaneous increase in R\&D spending directed towards those areas (in which case, the propensity to patent in such areas has remained unchanged). Using a different approach, Cohen et al. (2000) construct a "patent propensity" measure based on the responses of R\&D lab managers to questions in the Carnegie Mellon survey. Although the authors are able to construct a useful estimate of firms' propensity to patent at one point in time, they are unable to track annual changes in this important variable for respondents over time.
} 
specialization within the industry and lead to the emergence of 'technology specialists' (Merges 1998; Arora 1995). We examine this "specialization" hypothesis by assessing whether the surge in patent propensities in this industry is explained by the emergence of more patent-intensive design firms.

Several important findings emerge from our research. First, estimating firm-level patenting behavior during 1979-95 reveals that the upsurge in patenting by US semiconductor firms is indeed quite remarkable. Controlling for the changes in the mix of firms leaves the upward trend shown in Figure 1 essentially unchanged. Second, our qualitative and quantitative evidence suggests that the "pro-patent" shift has in fact contributed to intensified patenting in this industry, but in ways not examined systematically in previous studies. On the one hand, we find that large-scale manufacturers have invested far more aggressively in patents during the period associated with strong US patent rights, even controlling for other known determinants of patenting (consistent our "strategic response" hypothesis). Instead of being driven by a desire to win strong legal rights to a standalone technological prize, these firms appear to be engaged in "patent portfolio races" aimed at reducing concerns about being held up by external patent owners and at negotiating access to external technologies on more favorable terms. On the other hand, we find that firms entering the industry since 1982 patent more intensively than pre-1982 entrants. This is especially true of specialized design firms founded after 1982; in fact, we see a considerable increase in entry by this type of firm (consistent with our "specialization" hypothesis). ${ }^{9}$ Our interviews suggest that stronger patent rights are especially critical to these firms in attracting venture capital funds and securing proprietary rights in niche product markets.

Although these results highlight the multifaceted role that patents can play among firms even within the same broad technological area, we find that the primary reason for intensified patenting among our sample of semiconductor firms is more aggressive patenting by capitalintensive firms ("strategic response"). The results of our econometric analysis corroborate views commonly expressed by industry representatives that the 1980s "pro-patent" shift in the US legal environment altered their firms' incentives to patent. Nonetheless, in their analysis of the overall surge in US patenting during this period, Kortum and Lerner (1998) pose two alternative hypotheses that we also consider. First, Kortum and Lerner suggest that the surge in US patenting could be attributed to more aggressive patenting by firms endowed with large patent portfolios in the period preceding the CAFC's formation. Using aggregate trends in the patenting

\footnotetext{
${ }^{9}$ As discussed below, the emergence of specialized design firms into the industry was also facilitated by the adoption of standard process technologies used in semiconductor manufacturing (see Macher et al. 1998). An interesting question for future research is the extent to which this shift in process technology was itself facilitated by the "pro-patent" changes in the legal environment.
} 
and R\&D data, the authors find little support for their "regulatory capture" hypothesis. We too find little evidence that the even more dramatic surge in patenting by semiconductor firms is driven by scale effects alone or by more aggressive post-1982 patenting by Texas Instruments, the one firm in our sample with large absolute levels of patents in the pre-1982 period. We then consider a second alternative explanation posed by Kortum and Lerner, which we refer to as their "unrelated managerial improvements" hypothesis. It is possible that the increased patenting per $\mathrm{R} \& \mathrm{D}$ dollar that we observe in this industry is unrelated to stronger US patent rights and is driven by more general technological and managerial changes that have improved the productivity of the research process. Through a process of elimination, Kortum and Lerner (1998) conclude that this explanation is most consistent with patterns revealed in the aggregate data. We explore this issue at some length in our interviews and empirically test this important alternative hypothesis in the context of the semiconductor industry using firm-level data in Section 5. We too find evidence of managerial improvements during the period of our study, but primarily in the way semiconductor firms manage their intellectual property strategy rather than by changes in R\&D management.

The paper is organized as follows. In Section 2, we discuss the shift toward stronger US patent rights during the 1980s and highlight recent empirical studies that have examined its effects on the patent propensities of firms. In Section 3, we focus more narrowly on the role of patents in the semiconductor industry and present the results of our interviews. Section 4 contains the econometric analysis, describes the data and methods we use, and presents our results. In Section 5, we examine the alternative hypothesis that the intensified patenting in this industry stems from factors unrelated to the strengthening of US patent rights. Brief concluding remarks follow.

\section{The Institutional Change and Its Anticipated Effects}

The patent system has long been recognized as an important policy instrument used to promote innovation and technological progress. Two fundamental mechanisms underpin the patent system. First, an inventor discloses to the public a "novel", "useful", and "non-obvious" invention. In return, the inventor receives the right to exclude others from using that patented invention for a fixed period of time (now 20 years from the date of patent application in the United States). The rules of the patent game may differ from country to country (e.g., whether rights are assigned to the first inventor or the first to file the patent application), but the underlying principle remains the same. By providing exclusionary rights for some period of time and a more conducive environment in which to recoup $R \& D$ investments, the patent system aims to encourage inventors to direct more of their resources toward $R \& D$ than would otherwise be the 
case. At the same time, detailed information about the invention is disclosed to the public when the patent application is published.

\subsection{The Shift Toward Stronger US Patent Rights}

In the early 1980s, important changes in the US legal environment effectively strengthened the rights conferred to holders of US patents. In particular, the 1982 creation of the Court of Appeals for the Federal Circuit, a centralized appellate court, not only unified the judicial treatment of patent rights in the United States, but transformed the US legal environment from one that was generally skeptical of patents to one that promoted the broad, exclusive rights of patent owners (Adelman 1987; Merges 1997). For example, the new court endorsed the broad exclusionary rights of patent owners through its interpretation of patent scope and made it more difficult to challenge a patent's validity by raising evidentiary standards (Merges 1997). The court was also more willing to grant preliminary injunctions to patentees during infringement suits (Lanjouw and Lerner 1996), to sustain large damage awards (Merges 1997; Kortum and Lerner 1998), and to issue rulings that have been collectively construed as "pro-patent." Plaintiff success rates in patent infringement suits also increased substantially during this period (Lerner 1995).

Although the importance of the CAFC in strengthening US patent rights has been widely noted, the actual effects of "pro-patent" shift on the patent propensities of firms remains unclear. ${ }^{10}$ To the extent that stronger patent rights enable firms to recoup more of their R\&D dollars, stronger patent rights should increase incentives to invest in R\&D. ${ }^{11}$ But there is no $a$ priori reason to expect that these increased $R \& D$ dollars should yield proportionally more patents. For example, Appendix A shows that a firm facing a menu of patentable R\&D investment projects, each of which is subject to diminishing returns and which incurs a small cost for taking out each patent, will choose to increase both $R \& D$ and patenting when rights are strengthened; the ratio of patents to $R \& D$ will fall slowly as patent strength is increased over a wide range of patent strengths (where patent strength is interpreted in the conventional way to mean an increase in the gap between returns with a patent and returns without). Thus, unless other changes in the content or management of R\&D occurs (such as a shift toward more

\footnotetext{
${ }^{10}$ See Jaffe (2000) for a thoughtful discussion of the shift in US patent policies during the 1980s and the mixed empirical evidence on its effects on innovation more generally.

${ }^{11}$ Indeed, a central concern in the literature on optimal patent design is that firms would engage in socially wasteful "patent races" and over-invest in R\&D under a regime of strong patent rights. See Reinganum (1989) for a review of this extensive literature. Recent studies have advanced the patent-design literature by investigating the R\&D incentives provided by patents when innovation is cumulative, rather than discrete, in nature (e.g. Scotchmer 1991, 1996; Green and Scotchmer 1995; Scotchmer and Green 1990; O'Donoghue et al. 1998; and O'Donoghue 1998). Much of this work still suggests that strengthening patent rights (through a variety of mechanisms) should induce R\&D spending, albeit by initial innovators in the cumulative chain.
} 
"applied," patentable activities or improvements in research methods that speed or ease the inventive process), stronger patent rights should not necessarily generate an increase in the numbers of patents generated per R\&D dollar.

In light of the above discussion, it is interesting to note that previous empirical studies have failed to find evidence that the strengthening of US patent rights during the 1980s stimulated industrial spending in R\&D. Kortum and Lerner (1998) demonstrate that upswing in US industrial R\&D spending predates 1982. Moreover, they find that the intensity of research effort leveled off in the late 1980s and early 1990s while patenting rates continued to climb. In another study, Bessen and Maskin (2000) show that real R\&D intensity in information technology-related industries (including semiconductors, telecommunications, and computers) has fallen steadily since around 1982, providing little evidence that the strengthening of patent rights stimulated R\&D spending by firms in these industries. Similar evidence exists for the firms in our sample: incumbent firms (those who entered the industry prior to 1983) show a slight decline in their $R \& D$ intensity, whereas entrants (half of whom are design firms, which specialize in R\&D) show some increasing $R \& D$ intensities at first and then a decline. Thus, the surprising first order effect of the "pro-patent" shift in many industries seems to be an increase in patenting rather an increase in R\&D spending per se. ${ }^{12}$

\subsection{Exploring the link between the "pro-patent" shift and intensified US patenting}

The study by Kortum and Lerner (1998) previously cited examines these somewhat puzzling empirical trends in more detail in order to determine whether, in fact, the "pro-patent" shift led the continued explosion in US patenting or whether the two are simultaneous, but unrelated events. Their central hypothesis, like ours, is that the surge in patenting is related to this strengthening of US patent rights associated with the 1982 formation of the CAFC (their "friendly court" hypothesis). The authors test this hypothesis by examining evidence on worldwide patenting; if US patents in general have become more valuable because of the "propatent" shift, then the United States should have become a more important "destination" country for international patent filers following the CAFC's formation. They find little support for this hypothesis in the aggregate data and reject the view that the overall surge in US patenting is linked to the strengthening of US patent rights in the early 1980s. Kortum and Lerner also find little evidence for a variant of their "friendly court" hypothesis, which suggests that incumbents with large patent portfolios in the pre-CAFC account for the subsequent increase in patenting

\footnotetext{
${ }^{12}$ Due to the omission of other factors that may have impacted firm-level R\&D spending, however, one should be cautious about drawing strong conclusions from these aggregate time series data alone.
} 
(their "regulatory capture" hypothesis). ${ }^{13}$ Through a process of elimination, Kortum and Lerner (1998) conclude that the surge in US patenting over the past two decade appears to stem from a "broad increase in $R \& D$ productivity." In this view, the historically unprecedented rise in US patenting rates since the 1980s is in fact unrelated to the simultaneous changes in the US legal environment. Instead, it appears to be driven by more general "improvements in the management or automation of the innovation process itself" (Kortum and Lerner 1998, p. 4).

Kortum and Lerner (1998) highlight an important phenomenon, but their use of aggregate, rather than firm-level data, may have led them to dismiss the potential effects of the "pro-patent" shift too quickly, at least in the context of the semiconductor industry where the surge in patenting (relative to firm-level R\&D spending) is most dramatic. In semiconductors, we would modify the analysis of Kortum and Lerner in several ways. First, it is clear from talking with industry representatives that regulatory capture (implying a more aggressive use of intellectual property rights by large firms with deep pockets) could induce other firms to patent more aggressively in order to improve their negotiating position with these large owners of intellectual property. If this is true, regulatory capture does not necessarily imply that large patent owners will have a greater relative incentive to patent than firms most subject to "hold up" (either by large patent owners or a more diverse set of entities) in the era of strong patent rights. We examine this "strategic response" hypothesis below.

Second, we interpret changes in the "management of R\&D" more broadly. Even with few changes in the strategy and goals of their R\&D programs, it was clear from our conversations that many manufacturers had decided to "harvest" more patents from their R\&D, both as a defensive strategy (e.g., "to ensure the freedom to design and manufacture") and to assist them in winning favorable terms in cross-licensing negotiations with other firms in the industry. The results of the 1994 Carnegie Mellon Survey of Industrial R\&D in the United States (Cohen, Nelson, and Walsh 2000) highlight the importance of these broader motives for patenting among firms engaged in cumulative, "complex" technologies, including but not limited to semiconductors. ${ }^{14}$ This finding has important implications, not only on the broader use of patents by firms in many high technology industries, but on unraveling the potential effects of strengthening patents rights in areas where the value of a single patent is inherently tied to the value of other patented and

\footnotetext{
${ }^{13}$ Kortum and Lerner (1998) pose a fourth, "fertile technologies" hypothesis but also find little support in the overall data to suggest that the growth in US patenting is concentrated in "fertile" areas such as biotechnology or software.

${ }^{14}$ Other "complex" industrial settings included computers, electrical equipment, instruments, transportation and machinery (Cohen et al. 2000). These "complex" areas contrast with more "discrete" settings, such as chemicals, pharmaceuticals, or textiles where the value of one firm's patents are less inherently tied to the technologies of others (Cohen et al. 2000).
} 
unpatented technologies. We explore the implications of these issues at some length in our interviews and empirically in Section 5.

Finally, the "pro-patent" policies put in place by the CAFC may have facilitated entry by firms specializing in R\&D-intensive inputs even within existing industries (Merges 1998; see also Arora and Fosfuri 1998). Indeed, the period associated with strong US patent rights has witnessed significant entry into the semiconductor industry by firms that specialize in innovative products but that contract out the manufacture of their products to other firms. ${ }^{15}$ To the extent that product innovations are generally better suited to protection with patents (Levin et al. 1987), we might expect these firms to exhibit a relatively high propensity to patent based on their R\&D spending. Moreover, as 'technology specialists', these firms may rely more heavily on patents to appropriate returns to innovation than firms owning complementary assets in manufacturing (Teece 1986). It is possible therefore that the increased propensity to patent we observe in this industry is driven by the emergence of these patent-intensive firms. With this in mind, we explore the importance of patents to design firms in our interviews and return to this "specialization" hypothesis in our econometric analysis.

\section{Field Interviews}

In order to illuminate the factors that have influenced patenting in the semiconductor industry and the effects, if any, of the "pro-patent" shift on the innovative activities of different types of firms, we met with intellectual property managers and executives from seven semiconductor firms, including four manufacturers and three design firms. ${ }^{16}$ As shown in Appendix B (Table 1), the interview sample includes a range of firms in terms of size and patent intensity. Only one firm, Texas Instruments, held a large patent portfolio (both in absolute terms

\footnotetext{
${ }^{15}$ These specialized firms, which are known in the industry as "fabless" firms, design new microelectronic products but subcontract out the manufacture of these products to so-called "foundries," which often to specialize in wafer fabrication. Division of labor in this industry was aided by the diffusion during the 1980s of the Metal-Oxide Semiconductor (MOS) production technology. The adoption of the MOS standard enabled chip designers to operate within more stable design rules and foundries to incrementally improve their processes in ways that would accommodate successions of new designs (Macher et al. 1998).

${ }^{16}$ We conducted these interviews (which included structured questions and a follow-up survey) between April 1998 and November 1998. In each case, we asked to meet with someone with direct responsibility for formulating and implementing the firm's patent strategy. Identifying relevant decision makers was straightforward for small firms: we typically met with someone with a legal/engineering background who was in charge of the firm's patenting activities; in one case, we met with the firm's CEO. For larger firms, we typically met with two or more persons, including inhouse patent or corporate attorneys, patent licensing executives, or R\&D lab managers. In order to gain additional views on whether the firms in our sample are representative of industry-wide or cross-industry trends, we also met with attorneys actively involved in negotiating patent-related transactions on behalf of a broad set of firms, including ones in the semiconductor industry. For more information on these interviews and our results, see Ziedonis (2000).
} 
and relative to its R\&D spending) prior to the shift in US patent policies. ${ }^{17}$

Without exception, interviewees emphasized that the stronger patent rights ushered in by the Court of Appeals for the Federal Circuit (CAFC) reshaped the incentives to obtain US patents in this industry. But the implications of the "pro-patent" shift appeared to differ among the types of firms in the interview sample, depending on the size and strength of their patent portfolios in the early 1980s, and the extent to which other patent owners could credibly threaten to exclude the firm from using critical technologies and demand higher royalties for the use of external technologies. Despite the small number of firms in the interview sample, questions about the perceived effects of the early-1980s shift in US patent policies generated a rich set of general findings (see Ziedonis 2000 for more information). Here, we focus on differences between manufacturing firms and design firms that inform our econometric analysis below.

\subsection{Large-scale manufacturers: the increased value of patents as bargaining chips}

Several large-scale manufacturers in our sample were visibly "ramping up" their patent portfolios and "harvesting" latent inventions to add to their stock of patents. For example, one firm had "shifted from owning a total of 30 patents [in 1990] to filing over 300 patents in one year" with an internal goal in place to "own 1000 patents by the year 2000." Another manufacture had instituted an even more ambitious " 1000 by 2000 " patent goal while maintaining a relatively stable R\&D budget: before 1993, the firm typically filed 100 patent applications per year (which rose to 650 patent applications in 1996 to a goal of 1000 applications filed in a single year by 2000). The increased volume of patent filings appeared to reflect a deeper reach into an existing pool of inventions rather than a shift in R\&D activities per se. As one interviewee noted, there were "a lot of patentable inventions sitting around," but the firm had simply "not taken the time and incurred the cost" to patent these inventions in the past.

Two events, both related to the more favorable judicial treatment of US patent rights, were frequently mentioned as having played a pivotal role in reshaping the patent strategies of these firms. First, interviewees emphasized the important "demonstration effect" of Polaroid's successful patent infringement suit against Kodak; in 1986, Polaroid was awarded almost \$1 billion in damages and Kodak was barred from competing in the instant-film camera business. The large penalties imposed in this case and the realization that US courts were willing to take an aggressive stance against infringement by halting - either temporarily or permanentlyproduction utilizing infringed technologies fueled concerns among executives in many firms,

\footnotetext{
${ }^{17}$ Because of it pivotal role in setting industry-wide norms in the patent and patent licensing arena, Texas Instruments was included in our interview sample. We are treating the names of the remaining firms as confidential,
} 
including semiconductor manufacturers. As one interviewee noted, "a preliminary injunction would be detrimental to a firm if it means shutting down a high-volume manufacturing facility; loss of one week's production alone can cost millions of dollars." ${ }^{18}$ The licensing director of another firm agreed that the threat of injunction is indeed a powerful lever against manufacturers - especially if the cost associated with halting their production is high and they have already integrated the technologies into their production processes. The more costly and difficult it is for the infringing party to "invent around" the patented technology, the more favorable the negotiating position of the party who owns the legal "right to exclude".

A second widely-cited reason for intensified patenting in the industry was referred to by some as a "Texas Instruments" effect. During 1985-86, Texas Instruments successfully asserted its patents in court for a range of inventions pertaining to integrated circuits (e.g., the "Kilby patent" on the basic design of the integrated circuit) and manufacturing methods (e.g., the method for encapsulating chips or transporting wafers from one manufacturing platform to another). Although the original suits were against non-US firms, TI's successful enforcement of its patents enabled the firm to charge higher royalty rates to other firms in the industry. Indeed, interviewees were well aware of the strategies that Texas Instruments had put in place to manage - and profit from-its patent portfolio ${ }^{19}$; representatives from several firms plan to adopt a similarly aggressive licensing strategy once their portfolios grow larger. Others noted that AT\&T, IBM, and Motorola began asserting their patent rights more aggressively during this period in order to increase licensing revenues based on their large portfolios of semiconductor-related patents. According to several industry representatives, these large patent owners not only increased royalty rates for "rights to infringe" their patents but sought royalty-bearing licenses from smaller firms more aggressively. ${ }^{20}$

Citing these effects, interviewees from large-scale manufacturing firms typically noted that patents had become far more important to their firms during this "pro-patent" environment to use as bargaining chips in negotiations with other patent owners. Some noted that the

pending approval from interview participants.

${ }^{18}$ Until the Kodak-Polaroid case, infringing firms generally expected to pay royalties on past use of the property covered by the infringed patent (a reasonable risk and slightly less expensive in an expected value sense than paying royalties from the beginning); in contrast, after the Kodak-Polaroid ruling, firms perceived that they could be shut down with an injunction rather than simply paying the infringed firm. See Barton and Parapatt (1998) for additional information on the Polaroid-Kodak dispute.

${ }^{19}$ After launching its more aggressive patent licensing strategy in 1985, TI subsequently earned almost \$2 billion in royalty income during 1986-1993 (Grindley and Teece 1997).

${ }^{20}$ One report suggests that during 1987-88 IBM increased its typical royalty rates from 1 to 5 percent of sales revenues for products based on IBM patents (Shinal 1988). Although not mentioned in our interviews, the dramatic growth in overall semiconductor sales may have heightened further the incentives of patent owners to seek sales-based royalties during this period. From 1980 to 1990, for example, worldwide semiconductor sales increased from $\$ 13.6$ to $\$ 57.5$ billion (ICE Status Report 1998). 
semiconductor industry has historically been characterized by the broad, cross-licensing of patent rights among manufacturers. To a large extent, this is still the case (as discussed in Grindley and Teece 1997). Nonetheless, a firm lacking a strong patent portfolio of its own with which to negotiate licensing or cross-licensing agreements could face a more rapid erosion of profits in an era when the costs and risks associated with infringement had increased. For example, one industry executive estimates that "a new manufacturer would need to spend $\$ 100$ - \$200 million of revenues to license what are now considered basic manufacturing principles but which do not transfer any currently useful technologies." 21

Two factors emerged from these interviews that appeared to exacerbate these general "hold up" concerns among large-scale manufacturers in the semiconductor industry. First, these firms were investing in more costly facilities that were becoming obsolete more rapidly. For example, in the early 1980s, a wafer fabrication facility (fab) cost about $\$ 100$ million and had an expected life span of 10 years. By the mid-1990s, however, the cost had risen to over $\$ 1$ billion for a new fab, while the useful life of the capital investment had been reduced to little more than 5 years (ICE 1995). Semiconductor manufacturing is also notoriously complex, integrating an array of process and product technologies that cover aspects of the circuitry design, materials used to achieve a certain outcome, and methods used in the wafer fabrication process (see Ham et al. 1998; Grindley and Teece, 1997). As some pointed out, a given semiconductor product (say, a new memory or logic device) will often embody hundreds if not thousands of "potentially patentable" technologies that could be owned by suppliers, manufacturers in other industries, rivals, design firms, or independent inventors. With the strengthening of US patent rights, the expected benefits of amassing portfolios of "legal rights to exclude" (for offensive and defensive reasons) began to outweigh their costs. ${ }^{22}$

\subsection{Design firms: securing rights in niche product markets?}

The "bargaining chip" role of patents was less apparent in our interviews with the firms specializing in the design of semiconductor products. Two highly profitable design firms in our interview sample had established sophisticated in-house patent committees and were patenting

\footnotetext{
${ }^{21}$ Michael Rostoker, former vice president of strategic alliances as LSI Logic, as cited in Headley (1998: p. 17).

${ }^{22}$ Although some licensing agreements are negotiated using a list of the firm's "proud patents" (Grindley and Teece 1997), according to the industry representatives with whom we met, firms occasionally find patents so difficult to value that some cross-licensing negotiations are conducted using patent counts as the unit of currency. Von Hippel's interviews of semiconductor firms revealed a similar tendency: "[when] threatened by an infringement suit, a firm will typically send 'a pound or two' of copies of patents germane to the business to the potential plaintiff and suggest that it is they who are the real infringers, culminating in a cross-licensing" (von Hippel 1988, p. 53; cited in Cohen et al.

2000). Clearly, to the extent that this practice has become more widespread, there is a considerable incentive to apply for patents on minor innovations that have no other intrinsic value.
} 
aggressively in their core product lines. Unlike manufacturers, these firms appeared to be driven by a desire to secure broad proprietary rights to technologies in niche product markets. Although one firm was starting to patent for defensive reasons (i.e., in anticipation of future requests from larger firms for royalty payments), patents were mainly used to improve these firms' competitive position vis-à-vis direct market rivals. The small number of design firms in our interview sample negotiated surprisingly few licensing agreements involving the sale of rights to infringe their patented technologies or the acquisition of such rights from others. Put differently, patent rights appeared to be more important to these firms for "horizontal" reasons (to gain market share from rival firms) than for "vertical" reasons, such as exchanging know-how or technology with either suppliers of their manufacturing services or customers (Arora and Fosfuri 1998; Arora 1995). The primary "vertical" role of patenting for this small group of firms appeared to be in securing capital from private investors in the start-up phase. ${ }^{23}$ Even the executives at the large manufacturing firms with whom we spoke were aware of the importance of this role for patents in facilitating entry.

The overall picture that emerged from both sets of interviews was the importance of patents as an imperfect but quantifiable measure of technology that enabled technology-based trades to be made in external markets, both in financial markets (venture capital) and with suppliers and owners of complementary technologies. Although the sample underpinning these interviews is not necessarily representative of the industry as a whole, the general insights suggest that the shift in patent policies in the early 1980s increased the incentives of firms in this industry to patent (with notable exceptions; see Ziedonis 2000), albeit for reasons that differ among types of firms.

\section{Empirical Analysis}

Conclusions from our interviews with participants in this industry are necessarily limited by the size of the sample and the retrospective nature of the some of the questions. In this section, we examine the patenting behavior of a much larger sample of semiconductor firms over a period that spans the "pro-patent" shift in the US legal environment in order to ascertain the generality of our earlier findings. Our approach here is primarily econometric rather than qualitative, and we rely primarily on data that is publicly available (accounting data including R\&D spending, and

\footnotetext{
${ }^{23}$ A separate interview with a member of the board of a recent start-up firm highlighted the salience of these remarks. The design firm, which was established in 1994 and is still privately held, spends over $\$ 360,000$ a year on filing patent applications and related legal costs, or almost $40 \%$ of its annual revenues. According to the board member interviewed, investors demanded that the firm acquire strong patent rights at an early stage in order to increase its leverage against future rivals and to reduce the likelihood that the small management and engineering team would become distracted with patent infringement suits brought against the firm.
} 
patent grant data). In general, our results using the large sample of firms corroborate the main findings from our field research.

As mentioned in the introduction, Figure 1 suggests that US semiconductor firms have increased their "propensity to patent" since the mid-1980s. ${ }^{24}$ It is clear from this graph that there is a steep rise around 1985-86 in the patent applications obtained per million dollars of real R\&D spending in the semiconductor industry; the computing sector exhibits a similar rise, but it is much smaller, and the pharmaceutical/biotechnology industry actually shows a decline in the patent-R\&D ratio. ${ }^{25}$ While suggestive, these aggregate trends do not control for changes in the mix of firms during this period or for changes in other firm characteristics (such as size) that could affect the number of patents generated per R\&D dollar. It is also possible that the upward trend in Figure 1 simply reflects the well-documented, aggressive patenting behavior of Texas Instruments during this period. With this in mind, in this section we estimate a series of "patent production functions" that illuminate whether, in fact, a change in firm-level patenting behavior has taken place during the period associated with stronger US patent rights and that explore key differences among firms.

We test two main hypotheses. First, we examine whether firms most subject to "hold up" responded strategically to the shift in the US legal environment by patenting more aggressively during the period of strong patent rights (our "strategic response" hypothesis). Based on our interviews, firms with large sunk costs in complex manufacturing facilities appear to have the largest incentives to "ramp up" their patent portfolios in order to safeguard against the threat of costly litigation and to negotiate access to external technologies on more favorable terms. To test this hypothesis, we ask whether capital-intensity (a stock measure, defined below) influences the patenting behavior of firms in this industry and whether it has played a more prominent role in their patenting behavior in the period of strong US patent rights. Our second main hypothesis stems from the view that patent rights may have facilitated entry by design firms that rely more heavily on patents to appropriate returns to innovation (our "specialization" hypothesis). We test this hypothesis by (1) examining the changing pattern of entry in this industry and (2) investigating whether post-1982 design firms (i.e., ones that entered the industry during the "pro-

\footnotetext{
${ }^{24}$ Figure 1 shows the total patent yield for the 110 firms in our universe of Compustat SIC 3674 firms, together with the patent yield for all the firms in the Compustat manufacturing sector (firms whose principal SIC is between 2000 and 3999), and for firms in the other computing and electronics industries for comparison. The ratio of the total number of successful patent applications in the sector to the total R\&D spending in the sector is plotted rather than the average of the patent-R\&D ratios for each firm, to avoid the noise introduced by outlier observations with very small $R \& D$ programs. This procedure is equivalent to plotting a weighted patent-R\&D ratio where the weights are the size of the R\&D program.

${ }^{25}$ Note that we have all patents that issue by 1998 for our sample, but only those that issue by 1996 for the other industries, so our patent numbers are not quite complete in the later years. For this reason, we stop the analysis in Figure 1 in 1993, because 1994 appears to be the first year in which truncation due to the issue lag is visible.
} 
patent" era) rely more heavily on patent protection, controlling for other determinants of patenting.

In order to address the alternative "regulatory capture" hypothesis posed by Kortum and Lerner (1998), we control for the one firm in our sample, Texas Instruments, that held a large portfolio of patents in the pre-1982 period (both in absolute numbers and relative to other firms in the sample). This hypothesis also implies more aggressive patenting by large incumbents, an issue that we also explore. We return to the second alternative hypothesis raised by Kortum and Lerner (that the patterns we observe are driven by improvements in the research process unrelated to the "pro-patent" shift) in Section 5. Before describing the results of our analyses, we describe our data construction and the broad features of our data.

\subsection{Sample selection and data}

The econometric part of this study is based on the universe of 110 publicly traded U.S. owned firms whose principal line of business is in SIC 3674 (semiconductors and related devices) and who have data on Compustat between 1975 and 1996. To this universe we added a small number of publicly traded firms in related industries that we knew to be semiconductor firms. ${ }^{26}$ Because the purpose of this study is to examine changes in the patenting propensities of semiconductor firms over time, we needed reliable indicators for both the patented output of semiconductor firms and the semiconductor-related R\&D investments (inputs) of these firms. As discussed earlier, corporate R\&D spending is reported for a firm's entire portfolio of research activities, so we restricted our sample to firms whose $R \& D$ investments are primarily directed toward technologies aimed at semiconductor-related products. We therefore exclude "systems" manufacturers, such as AT\&T, Motorola, or IBM, that are important owners (and users) of semiconductor-related intellectual property but whose R\&D investments are broader in scope (e.g., directed towards telecommunications or computer technologies more generally). We excluded non-US firms (e.g., Hitachi or Samsung) for similar difficulties in obtaining reliable semiconductor R\&D investments for these firms; the patent propensities of non-US firms may also be driven by institutional factors of their home countries, which are beyond the scope of our study.

For the analysis in this paper, we restricted the sample to 1979 (the first year in which there are more than 20 firms) through 1995 (because of the truncation of the patent data after that date due to lags in the granting of patents), dropped partially-owned subsidiaries, and excluded firms that had less than 3 years of good data. The final sample, as shown in Appendix B (Table 
2), contains 95 firms in an unbalanced panel that has 946 observations (firm-years). The omitted firms were primarily small post-1994 startups for which we had inadequate data.

A major challenge in any study that examines the patenting activities of firms over time is identifying which patents are assigned to individual firms in a given year. Firms patent under a variety of names (their own and those of their subsidiaries) and the Patent Office does not keep a unique identifier for the same patenting entity from year to year. To construct the entity-level patent portfolios of the firms in our study, we first retrieved the patent portfolios of the firms included in the Case Western patent database (discussed in Hall et al. 2000). ${ }^{27}$ We supplemented these data with updated entity-level portfolios for the firms in our study by identifying name changes, subsidiaries, and mergers and acquisitions from a variety of sources. ${ }^{28}$ These searches generated a total of 17,228 patents issued to these 95 firms that were applied for between 1979 and 1995, for an average of 241 total patents per firm. In contrast, 519 patents were issued to the omitted firms, an average of 17 total patents per firm.

The entity-level patent portfolios were combined with each firm's detailed balance sheet and income statement data from Compustat. The resulting "matched" database combines, for all 95 firms, the front page patent information for their patents that issued during 1979-1995 (e.g., the patent number and class, the date the patent was applied for and issued) with information contained in Compustat (e.g., annual R\&D spending, capital expenditures, number of employees, and sales). In addition, we used business directories and industry sources to identify the founding date of each firm (which may precede the date for which we have data by many years), and to determine whether the firm owned and operated its own fab (manufacturer) or specialized in product design alone (design firm). ${ }^{29}$

Table 1 provides summary statistics for our key variables. The top panel is based on our universe of firms from 1965 to 1997 and the bottom panel is based on the sample we use for

\footnotetext{
${ }^{26}$ These additional firms were added based on information in volumes from ICE (1976-1998).

${ }^{27}$ This database contains the results of a match between the names of approximately 3,000 manufacturing firms on the Compustat files to about 30,000 of their subsidiaries (using a 1989 "Who Owns Whom" directory).

${ }^{28}$ We identified name changes and 1998 subsidiary information from Standard and Poor's "Corporate Descriptions Plus News" database available on Lexis-Nexis. Some firms were acquired or went bankrupt during the period of our study and were therefore not listed in current business directories. In this event, we retrieved the relevant information from the last available 10-K filed by the firm. We identified 1994 and 1989 subsidiaries of large firms by using the Directory of Corporate Affiliations ("Who Owns Whom"); for smaller firms, we obtained the list of 1994 and 1989 subsidiaries from the list of subsidiaries (typically, Exhibit 21) filed with each firm's annual 10-K report. Finally, we identified all major mergers and acquisitions involving these firms from 1984 to 1998 using several databases and directories available on Lexis-Nexis, including: the Financial Times Mergers and Acquisitions Database, the IDD United States M\&A Transactions database, and the "news" portion of "Standard and Poor's Corporate Description Plus News" database.
} 
estimation. The median firm in our sample is 24 years old in 1995, has approximately 500

employees, spends five million (1992) dollars on R\&D, and successfully applies for one patent a year. ${ }^{30}$ The distribution of these variables is quite skewed, however, with over 700 patent applications in one year for one firm (Texas Instruments in 1995) and over one billion dollars of $R \& D$ in one year for one firm (Intel in 1994 and 1995). Design firms represent 20 percent of the observations. $^{31}$

\subsection{Estimating the patent production function}

To explore the determinants of patenting in these semiconductor firms and how they have changed over time, we use a patent production function first introduced by Pakes and Griliches (1980); our specific econometric model was first applied to patent data by Hausman, Hall, and Griliches (1984). The patent production function relates the number of successful patent applications made by a firm in a given year to its past history of R\&D spending, along with other firm characteristics such as size.

Because the number of successful patent applications made by a semiconductor firm is a count variable with many zeroes and ones, we use Poisson-based econometric models and estimation methods. As in Hausman, Hall, and Griliches (1984), we hypothesize that the expected number of patents applied for during the year is an exponential function of the firm's R\&D spending and other characteristics $X_{i t}$ :

$$
E\left[p_{i t} \mid X_{i t}\right]=\lambda_{i t}=\exp \left(X_{i t} \beta+\gamma_{t}\right)
$$

where $i$ indexes the firm and $t$ indexes the year. $\gamma_{t}$ is an overall year specific mean that measures the average patenting rate across all firms, adjusting for the changing mix of firms in the sample. We estimate this model using maximum likelihood for the Poisson distribution, but we report "robust" standard errors. Gourieroux, Montfort, and Trognon (1984) have shown that the Poisson coefficient estimates are consistent if the mean specification is correct, because the Poisson model

\footnotetext{
${ }^{29}$ We used the business directories on Lexis-Nexis (discussed above) to identify the year in which each firm was established. To determine whether a firm was a manufacturer or not, we used 1997 industry data provided by Integrated Circuit Engineering, Inc. (ICE) in which a firm is classified as "fabless" if the majority of its wafers are manufactured by other parties. Because some of our firms had manufacturing capabilities at one time but had divested them by 1997 , we supplemented these data by examining previous 10 -Ks for each firm.

${ }^{30}$ As discussed below, these data include information on these firms' successful patent applications (i.e., applications for which patents are eventually granted). Information on unsuccessful US patent applications (i.e., ones that do not result in issued US patents) is not publicly available in the United States.

${ }^{31}$ A small number of observations are missing R\&D in one or more years, although all the firms in our sample report $\mathrm{R} \& \mathrm{D}$ in at least some years. To a great extent, the firms dropped in our cleaning process were younger (often because they actually entered in 1994 or later) and smaller.
} 
is in the linear exponential class, and that the robust standard errors will be consistent estimates even under misspecification of the distribution.

We also report the results of a Lagrange multiplier test due to Cameron and Trivedi (1998) for overdispersion of the negative binomial (2) type. ${ }^{32}$ Rejection can be interpreted as a rejection of the pure Poisson model in favor of a model where the variance is proportional to the mean. However, because the negative binomial model estimates would be inconsistent if the true distribution were not negative binomial, we prefer to interpret the LM test as a diagnostic that indicates that we should report robust (heteroskedastic-consistent) standard errors for the Poisson model (which will remain consistent) rather than implying that we should actually switch to a negative binomial model (which is potentially inconsistent).

The coefficients from the patent production function model presented above have an elasticity interpretation:

$$
\left(1 / \lambda_{i t}\right)\left(d \lambda_{i t} / d X_{i t}\right)=\beta
$$

and the changes in the $\gamma_{\mathrm{it}}$ s measure the growth of the patenting propensities over time that is not accounted for by changes in the firm's characteristics:

$$
\Delta \log \lambda_{i t}=X_{i t} \beta+\gamma_{t}-\left(X_{i t-1} \beta+\gamma_{t-1}\right)=\Delta X_{i t} \beta+\gamma_{t}-\gamma_{t-1}
$$

Thus the growth of the expected number of patents can be decomposed into the growth due to changes in firm characteristics and a residual growth rate $\gamma_{t}-\gamma_{t-1}$, which we interpret as being due to changes in the patenting environment faced by these firms.

Traditionally, the most important variable in the patent production function is $R \& D$ spending by the firm, and much of the early work that estimated this model focused on the question of whether one could measure the lag structure for the production of patents from past R\&D spending. ${ }^{33}$ This literature largely concludes that the lag structure is very poorly identified because of the high within-firm correlation of R\&D spending over time. When many lags are included in the model, the estimate of the sum of the coefficients is roughly the same as the

\footnotetext{
${ }^{32}$ All the estimates in the paper were obtained using the POISSON, NEGBIN, and ML procedures in TSP Version 4.5. See the TSP Reference Manual (1999) for details on the estimation strategy. The results of this procedure have been benchmarked against published results in Cameron and Trivedi (1998) and in Hausman, Hall, and Griliches (1984).
} 
estimated coefficient of contemporaneous $R \& D$ when no lags are included; in addition, most of the contribution comes from the oldest and the newest R\&D lag included. For this reason and because many of our firms have very short R\&D histories, we use contemporaneous levels of R\&D spending in our specifications. ${ }^{34}$

A second result in the previous literature on patent production is that when one allows for permanent differences across firms in the propensity to patent, the sum of the R\&D lag coefficients falls, mostly because the coefficient on the oldest lag becomes insignificant. In our study, we expect the role of firm effects to be somewhat less since all the firms are in the same rather narrow industry. In addition, for some of our hypotheses, we are interested in the firm effects themselves (for example, the difference between design and manufacturing firms, or the difference between incumbents and entrants), and so we do not want to begin with a model that sweeps them out. In Appendix C, we present evidence that the impact of permanent differences across firms is in fact modest.

Our base specification of the patent production function includes the following variables:

- $\quad$ R\&D spending during the year in which the patent applications were filed, deflated in 1992 dollars, in logarithms. When employment (size) is also included, we normalize R\&D spending by the number of employees, to avoid confounding the $R \& D$ effect with the size effect. For a small number of observations, $R \& D$ is missing or not reported; we include a dummy variable for these observations so that the R\&D coefficient will not be biased.

- The size of the firm, measured as the logarithm of employment. As previous studies have documented, there may be economies of scale in generating patents, due to the fixed cost of maintaining a legal department that can handle intellectual property questions (confirmed in our interviews; see also Lanjouw and Lerner, 1998; Lerner, 1995).

- The capital-intensity of the firm, measured as the logarithm of the ratio of deflated (1992\$) plant and equipment to employees (i.e., capital-labor ratio).

- Annual time dummies for 1979-1995.

After presenting the base specification, and discussing the results, we augment our specification with a series of variables that explore the differences in the patent equation for firms of various types:

- An entrant dummy, for firms that were founded after 1982 (the year that CAFC was created). There are 35 such firms with 185 observations.

\footnotetext{
${ }^{33}$ In addition to Pakes and Griliches (1980) and Hausman, Hall, and Griliches (1984), see Hall, Griliches, and Pakes (1986). For work that explores the econometric specification and estimation of this equation, see Montalvo (1997) and Blundell, Griffith, and Windmeijer (1997).

${ }^{34}$ Experimentation with lag structures using these data confirmed the results in the earlier literature.
} 
- A Texas Instruments dummy, which captures the fact that TI patents aggressively throughout our sample (relative to other firms in our sample, controlling for R\&D spending and size).

- The age of the firm, measured as the logarithm of the difference between the current year and the founding year of the firm (which can be earlier than the first year of our data set).

- The type of firm (manufacturer or design firm). By specializing in product innovation, design firms may patent more intensively than manufacturers (controlling for other factors). Our interviews nonetheless suggest that design firms and manufacturers patent for quite different reasons, an issue that we will want to explore. There are 28 design firms in the sample for a total of 192 observations.

\subsection{Basic results}

Table 2 presents a series of estimations of our basic model using maximum likelihood methods and the Poisson density function. ${ }^{35}$ As should be clear from the above discussion, the data set is a panel and the unit of analysis is a firm-year. Standard error estimates robust to heteroskedasticity and misspecification of the distribution are shown in parentheses. Column (1) shows that the estimated elasticity of patenting with respect to R\&D spending in this industry is similar to estimates previously obtained using data for the whole manufacturing sector in the 1970s, although somewhat higher. For example, Hausman, Hall, and Griliches (1984) obtained an R\&D elasticity of 0.87 (0.004) using the Poisson distribution and an elasticity of $0.75(.02)$ and variance parameter of 0.04 (0.002) using the negative binomial distribution for 128 large firms. Hall, Griliches, and Hausman (1986) obtained a somewhat lower elasticity of 0.52 for a larger sample of 642 firms. In the latter case, the log of capital stock was also included in the equation and the total scale coefficient (the sum of the two coefficients) was 0.66 , somewhat closer to our estimate of 0.99 (0.04).

When we add firm size and capital intensity to the model and replace R\&D with the R\&D-employment ratio in column (2), the R\&D coefficient falls sharply because the size effect is now in the employment variable, but the scale coefficient is about the same (equal to 0.96). Thus there is no evidence of increasing returns in the patent production function. The explanatory power of the model also improves, with a substantial increase in the likelihood and a fall in the value of the overdispersion test statistic. Capital intensity does indeed seem to have an influence

\footnotetext{
${ }^{35}$ Because we are interested in examining observed differences in behavior across the firms in our sample, we do not allow for firm effects in our main analyses. In Appendix C, however, we present the results of estimations that allow for unobserved differences. We find that, in contrast to earlier results using these kinds of data that were based on a wide range of industries, the role of firm effects is somewhat diminished when we look within a rather narrow industry definition as we do here. Here, and in the remainder of the paper, we therefore allow only for observed permanent differences across firm-types.
} 
on the propensity to patent, one which is slightly larger and more significant that the influence of R\&D spending. This is consistent with our first (strategic response) hypothesis.

In column (3) we add dummies for post-1982 entry and for Texas Instruments (TI). The estimate for TI's patenting propensity reflects its well-known aggressive IP strategy: the firm obtains an average of 80 percent more patents than other firms in the sample, even controlling for its size, R\&D, and capital intensity. In column (3) and in the rest of the results in our paper, the patent equation is much closer to passing the overdispersion test; controlling for the unique nature of TI leaves us with a sample of firms whose patenting behavior is more consistent with the conditional Poisson model (that is, the variance conditional on firm characteristics is nearly equal to the conditional mean). Interestingly, firms that entered this industry during the pro-patent era have a $50 \%$ higher patenting propensity. Allowing for this fact also strengthens the impact of capital intensity. Later on, we provide evidence that this is because many of the new entrants are design firms, which patent relatively heavily but do not have manufacturing plants (consistent with our second hypothesis, "specialization")

The final column of Table 2 shows that neither the age of the firm nor whether it is design firm influences the propensity to patent, once we have controlled for the firms that enter in the pro-patent era (after 1982). It is essential to note that this would not be the case if we had omitted the post-1982 entrant dummy. We interpret this finding in part as a contradiction to the Kortum and Lerner regulatory capture hypothesis, which implies that incumbents should have a higher patenting propensity than entrants. Because the age of the firm and whether it is a design firm do not enter significantly in this equation, for the remainder of the paper we use the specification given in column (3) of this table, although we will revisit the design firm question later in Table 5.

The estimates in Table 2 yield another striking result, as shown in the figure at the bottom of the table. This figure plots the year dummies for the 4 sets of estimates, normalized so that they are equal in $1979 .{ }^{36}$ These estimates make it quite clear that controlling for changes in the mix of semiconductor firms over time does not undermine the rise in patenting propensity shown in Figure 1. The patent propensity of the firms in our sample increased at a steady rate of 10 percent per year after about 1986, somewhat later than the 1982 introduction of the Court of Appeals for the Federal Circuit, for a total increase of approximately 100 percent by 1995 . These results are consistent with the views expressed by industry representatives that the events most significant in altering their firms' behavior were the well-publicized Kodak-Polaroid case (1986) and the aggressive stance of TI with respect to its patent rights (which dates to about 1985-86), rather 
than 1982 formation of the CAFC in itself. Our overall conclusion from Table 2 is an overall shift in behavior has occurred, that capital intensity matters for patenting behavior and that entrants patent more than incumbents, other things equal.

\subsection{Changes in the determinants of patenting}

In order to examine whether the "pro-patent" shift in the US legal environment altered the determinants of patenting for firms in this industry, we would like to compare the behavior of firms both before and after the "regime shift" took place. The actual strengthening of US patent rights, however, involved a more gradual process by which court rulings were disseminated and upheld. Although the CAFC was created in 1982 and issued a flurry of written opinions during 1983 (Adelman 1987; Nies 1993), the impact of the CAFC on the favorable legal treatment of patent rights in US courts was not widely publicized until the mid-1980s. ${ }^{37}$ Representatives from semiconductor firms also emphasized the important "demonstration effects" associated with the successful patent infringement suits of Texas Instruments and Polaroid during 1985-6, as discussed in Section 3.

With this in mind, we selected three five-year intervals that allow for a more gradual "regime shift" toward stronger US patent rights. The first period, 1979-83, examines the patenting behavior of firms under the weaker patent regime. It implicitly assumes that the response of firms to the 1982 creation of the CAFC would require at least a one-year lag. ${ }^{38}$ The "during" period, 1984-88, spans years in which the "pro-patent" stance of the CAFC was widely heralded in the trade and business press and verdicts in the TI and Polaroid cases were reached. The final period, 1989-93, examines the determinants of patenting under the pro-patent regime.

In order to examine changes in the determinants of patenting across the three periods, the sample is restricted to the subset of semiconductor firms that were publicly traded before 1984 and for which data were available in each of the three periods. This selection criterion generated a sample of 34 incumbent firms. ${ }^{39}$ Table 3 presents the estimates of incumbents' patenting behavior

36 That is, $\gamma_{\mathrm{t}}-\gamma_{1979}$ is plotted.

${ }^{37}$ A series of articles surfaced in the popular press during 1985-86 that proclaimed the "new" legal environment for patent owners. See, for example, "A Change in the Legal Climate," Forbes, Oct. 7, 1985, p. 41; "A Weapon at Last [pro-patent decisions]," Forbes, Mar. 10, 1986, p. 46; and "The Surprising New Power of Patents," Fortune, June 23, 1986, p. 57.

${ }^{38}$ Excluding 1983 from this period did not substantively alter the results. The selection of 1979 as the lower bound of the "before" period reflects the fact that 1979 is the first year in which more than 20 firms in the sample report positive amounts of R\&D. Earlier years suffer from a lack of reliable R\&D data for a sufficiently large sample of firms, as discussed above.

${ }^{39}$ This definition of "incumbents" differs from the earlier one based on founding year, as presented in Table 3 . Unlike the earlier analysis, we want to restrict our attention here to the subset of firms for which it is possible to estimate behavior in all three periods. 
in each of the three five-year intervals. ${ }^{40}$ Consistent with the results reported in Tables 2, the estimates use maximum likelihood methods, a Poisson density function, and report standard errors that are robust to heteroskedasticity and misspecification of the distribution.

Overall, the results presented in Table 3 suggest that the strengthening of US patent rights has indeed altered the incentives of firms to patent, but for reasons that transcend those implied by a narrow role of patents as a mechanism by which to appropriate returns to R\&D. During the era of strong patent rights, these firms' decision to patent become less, not more, responsive to investments in R\&D. Consistent with the view that capital-intensive firms altered their behavior under the new pro-patent regime by patenting more aggressively, the coefficient of capitalintensity changes from small and insignificant in Periods 1 and 2 to positive and highly significant in Period 3.

Two other interesting results are contained in Table 3. First, Texas Instruments became less of an outlier in its patenting behavior over time. During 1979-1988, TI was twice as likely to file a successful patent application than other incumbents, all else equal. During 1989-93, however, TI was only $65 \%$ more likely to patent than other incumbents (all else equal). This result reflects the relative "catching up" by other incumbents, rather than a fall or leveling off in TI's absolute propensity to patent. A second interesting finding pertains to the relative stability of the size coefficient across the three periods, which casts further doubt on the "regulatory capture" hypothesis. Although large firms might enjoy economies of scale in applying for and enforcing patents, the elasticity of patenting with respect to firm size is quite similar in each period and in fact somewhat less than unity.

\subsection{Manufacturing versus design firms}

In Table 4, we revisit the question of whether the increase in patenting was driven by the behavior of capital-intensive manufacturers, who are arguably more subject to hold-up threats given their large investments in complex fabrication facilities or by the patenting behavior of an increasing number of design firms. To explore this, we show four variations of our basic specification: a separate intercept for design firms in column (1), different slopes for the two groups in column (2), separate trends in column (3), and separate trends and slopes in column (4). Robust chi-squared tests reject all hypotheses of coefficient equality, implying that a completely different patenting propensity equation is appropriate for the two groups of firms.

\footnotetext{
${ }^{40}$ The results were insensitive to either of the following changes: (1) a more restrictive definition of "incumbents" that included firms publicly traded before 1983 (instead of 1984) and (2) the inclusion of 8 incumbents that subsequently exited the sample during periods 2 or 3 .
} 
Table 4 contains two results that reinforce the view that stronger patent rights facilitated entry into the industry by specialized design firms for whom capital intensity is a relatively unimportant predictor of patenting behavior. The first result is that capital intensity is a much more important predictor of patenting propensity for manufacturing firms than for design firms (compare the elasticity of 0.64 for manufacturers versus 0.30 for design firms in the last column). The second result, which is even more prominent, is that once we allow for separate slopes for design firms, it is not post-1982 entry that predicts higher patenting but post-1982 entry by $a$ design firm, with a coefficient of $1.60(0.27)$. These firms are approximately $160 \%$ more likely to patent than the rest of the sample, controlling for their other characteristics. ${ }^{41}$ We view this as strong confirmation of our interviewees' statements that patent rights are required in order to secure venture capital and other financing for entry as a specialized semiconductor design firm.

A second piece of evidence on this question is provided in Figure 2, which shows the cumulative entry of both manufacturing and design firms into our sample. As can be seen from the figure, few design firms enter before 1986, and then the number surges upward (the curve flattens out in 1993 because of our requirement that a firm have three good years of data to be in our sample). Although this entry was enabled by the transition to the CMOS standard and the availability of foundry providers (Macher et al 1998), it is possible that the consequent fragmentation of the design and production process was facilitated by access to stronger patent rights.

\subsection{Summary of econometric results}

Our econometric study identifies at least two reasons for the surge in patenting per R\&D dollar in the semiconductor industry since the mid-1980s: increased patenting by capital-intensive manufacturing firms and increased entry into the industry by design firms that need patents on their technology to secure financing. But which of these two is more important for the aggregate behavior of the industry? Figure 3 provides an answer.

${ }^{41}$ Although one might have thought that post-1982 entrants and design firms have considerable overlap, there are a sufficient number of pre-1982 entrants that do not have fabrication plants for this equation to be well-identified. Here is the two way table for the observations in our sample:

Number of Firm-Years per Group

\begin{tabular}{c|c|c}
\hline & Manufacturing Firms & Design Firms \\
\hline Incumbent Firms & 672 & 89 \\
\hline Post-1982 Entrants & 82 & 103 \\
\hline
\end{tabular}


This figure shows the patent-R\&D ratio (weighted by $R \& D$ spending) for all firms in the industry and for manufacturing and design firms separately. ${ }^{42}$ The increase in this ratio in manufacturing tracks the ratio for the whole industry closely, whereas for design firms, the ratio is constant or even falling. Because the $R \& D$ in design firms is only 15 percent of the total $R \& D$ in the industry even in the later years, patents per R\&D dollar weighted by R\&D spending will be dominated by changes in the manufacturing part of the industry. Thus even though it appears that the pro-patent shift may have facilitated vertical disintegration in this industry, it is still the case that the primary reason for the increase in patenting per R\&D dollar is more aggressive patenting by manufacturing firms in our sample.

\section{Exploring Alternative Hypotheses}

In the previous sections, we have demonstrated that a surge in the patent propensities of semiconductor firms has occurred during the period associated with stronger US patent rights, and that the surge is driven by more aggressive patenting by large-scale manufacturers in our sample. In our opinion, these results are consistent with a variant of Kortum and Lerner's "friendly court" hypothesis, but one that allows for strategic behavior among firms. In an industry where the pace of technology is rapid, and innovation is cumulative, the strengthening of patent rights increases the risk that one holder of property rights can effectively exclude, or "block", another from using the technology embodied in the patent (Merges and Nelson 1990; Cohen et al. 2000). This concern appears especially salient among firms that have made costly and rapidly depreciating investments in facilities that use a "thicket" of innovations developed by many parties. In order to obtain the rights to infringe patents held by external parties and to improve their leverage in negotiations with other patent owners, these firms amass larger patent portfolios of their own with which to trade. With the strengthening of US patent rights, the expected benefits of owning US patents (for offensive and defensive reasons) began to outweigh their expected costs.

Although our empirical results and interviews with firms suggest that intensified patenting in this industry was driven by the "pro-patent" shift in the US legal environment, it is important to address whether the patterns we observe stem from unrelated managerial or technological improvements, as suggested more generally by Kortum and Lerner (1998). First, if firms have redirected more of their R\&D investments toward applied rather than basic research, we might also see an increased patent yield of $R \& D$ dollars over time. There was little indication

\footnotetext{
${ }^{42}$ The data in this figure are shown beginning in 1982 because there are very few design firms in the sample prior to that date (fewer than 5). The few that are there have a very high yield of patents to R\&D, which makes the rest of the
} 
from our interviews that such an industry-wide shift occurred that would explain the time trends that we observe. We did, however, find a general belief that it is remarkably easy for these firms to obtain patent rights from the US Patent and Trademark Office and, in the view of most representatives and executives we interviewed, the standards of patentability have been lowered (especially the standard that an invention must be "non-obvious" in order to be eligible for a patent award). ${ }^{43}$ Although the ease with which firms obtain patents may have increased over time, there is little reason to believe that procedures at USPTO would disproportionately favor patents in semiconductor-related technologies so this cannot be the sole explanation of the increase.

A related explanation for the surge in patenting is that firms have improved their ability to manage the innovation process and that the "productivity of R\&D" has therefore improved. Put differently, R\&D expenditures may have remained relatively stable while the patented "output" of that R\&D has increased due to managerial or technological improvements in the innovation process that are unrelated to the change in US patent policies. Through a process of elimination, Kortum and Lerner (1998) supported this view that "managerial improvements" (not the "friendly court" or a shift toward applied research) underpinned the cross-industry increase in US patenting.

Our interviews suggest a very different interpretation of the "managerial improvement" hypothesis, at least in the semiconductor industry. The surge in patents relative to R\&D spending may indeed reflect important managerial changes, but in how firms manage the $R \& D$ output, not necessarily the $R \& D$ input side of the innovation process. For example, several firms had overhauled their internal patent procedures during the past 5-10 years by hiring more in-house patent attorneys, rewarding engineers with bonuses for patented inventions, expanding the involvement of patent attorneys in corporate-wide activities, (such as strategic alliances, licensing, and litigation decisions), and creating in-house "patent committees" to oversee and simplify the otherwise time-consuming process of writing, filing, and revising patent applications. As mentioned earlier, manufacturers appeared to be "harvesting" more of their latent inventions and explicitly "ramping up" their patent filings in order to amass more sizeable patent portfolios. Although the increased sophistication of design tools may have aided firms' ability to innovate in the product areas, the most dramatic alteration in the internal processes appeared to be directed toward the management of the patent process itself.

graph hard to see if they are included.

${ }^{43}$ Hunt (1999) explores in more detail this apparent lowering of "non-obviousness" standards in the United States during this period, which may have added additional fuel to the "patent portfolio races" we observe in this industry. The combined effect of (a) strengthening enforcement and (b) lowering patentability requirements is an interesting topic for furture research. 
In order to test whether firms are applying for an increasing number of "lesser quality" patents over time (as implied by a "harvesting" strategy whereby firms are increasing their filings of marginal patent applications), or whether, in fact, the quality of their patent portfolios remains relatively constant over time (as implied by an increase in research productivity alone), we examine changes in the relative "quality" of these firms' patents over time. We use two very imperfect measures of patent "quality": the number of citations received by the patent ("forward" citations) and the number of claims in the patent. There is considerable support in the literature for the idea that the former measure is correlated with the private value of the patentable invention (see Harhoff et al 1999 and Hall et al 2000 among others). Lanjouw and Schankerman (1999) show that forward citations and claims are among the several correlated indicators of private value. However, it is also true that these indicators may be changing over time for reasons unrelated to quality. For this reason we compare the changes in these measures for our firms to the changes in U.S manufacturing firms overall, in order to control for secular changes in patenting and citation behavior.

Our evidence is weakly consistent with a "harvesting" strategy, but is sensitive to the quality measures employed. Using the average citations per patent measure, we find a slight decline in the average quality of our firms' patents since 1984, relative to the average quality of patents assigned to US manufacturers as a whole. Figure 4 shows that although semiconductor patents in general receive more citations than the average patent in manufacturing, the relative ratio fell from 1.5 to 1.4 during the $1980 \mathrm{~s} .{ }^{44}$ This result is consistent with the view that firms are filing larger numbers of lower quality patents during the period associated with stronger patent rights, in contrast to what the "R\&D productivity" hypothesis would imply.

However, Figure 5 shows this relative citation-per-patent measure with and without selfcitations (citations from patents held by the same firm) included. Clearly the propensity that other firms will cite patents held by semiconductor firms is rising, which could result if the increased likelihood of litigation in this industry has led to an increase in "defensive" citation aimed at delimiting more clearly the boundaries of the invention covered by the patent (see Jaffe, Tratjenberg, and Fogarty 2000 on this point). Thus we conclude that in the case of semiconductors and the pro-patent legal shift, changes in citations per patent potentially confound two opposite effects: declines due to lower quality patents and increases due to "defensive"

\footnotetext{
${ }^{44}$ We do not give significance levels for this finding due to the large number of observations involved, which means that the average citation-patent ratio is extremely well determined and any point hypothesis will be rejected. Estimates of the citation lag distribution using the Jaffe-Trajtenberg (1996) methodology and breaking out semiconductors pre and post-1984 from the other technologies (not shown) reject both the hypothesis that semiconductors have the same citation distribution as other industries and that post-1984 semiconductor patents have the same citation distribution as pre-1984 patents, using standard errors robust to heteroskedasticity.
} 
citation, rendering it difficult to draw definitive conclusions about the increased propensity to "harvest" inventions from this measure.

The claims-based measures of "quality" provide very little evidence of either an increase or a decrease in patent quality over this period (see Figure 6 for a plot of the average claims per patent by our semiconductor firms relative the average for all manufacturing). If anything, it seems to have risen slightly in the early 1980 s and then flattened out. ${ }^{45}$

Our conclusion from the examination of citations and claims for these semiconductor patents is that there is weak evidence at best for the hypothesis suggested by our interviewees, that the quality of the average patent in this industry as fallen. However, we caution that these measures are highly imperfect and contaminated by other changes in patenting strategy during the period. This is an area for future research.

\section{Conclusion}

A patent is a legal right to exclude. In an industry where the pace of technology is rapid and firms advance quickly (even simultaneously) upon innovations made by others, firms may patent for strategic reasons even if they continue to rely on other mechanisms, such as lead-time and superior manufacturing or design capabilities, to recoup investments in R\&D. Especially for firms engaged in rapidly changing, cumulative technologies, building larger portfolios of their own "legal rights to exclude" may reduce the hold-up problem posed by external patent owners and enable firms to negotiate access to external technologies on more favorable terms. But the importance of patent rights and their use may vary even among firms within the same industry over time.

This paper examined the patenting behavior of firms in one "cumulative technological" setting, semiconductors, where the gap between the relative ineffectiveness of patents as a means to profit from innovation (as reported in surveys) and their increasing use during a period associated with stronger US patent rights is particularly striking. By combining insights from interviews with intellectual property managers and executives from semiconductor firms with quantitative analyses of the patenting behavior of 95 US firms during 1979-1995, we identified two ways in which the "pro-patent" shift in the US legal environment may underpin the somewhat perplexing surge in US patenting rates, at least in the semiconductor industry. First,

\footnotetext{
${ }^{45}$ In some ways, these results demonstrate the difficulties of constructing representative "control" groups with which to compare the behavior of firms within the same technological area over time. In these measures, we compared the claims contained in and citations received by semiconductor firms' patents with corresponding indicators for all US manufacturers. An alternative approach would be to examine change in our sample firms' patent filings in the United States and in a patent system that screens out marginal patent applications more carefully (e.g., the European or German Patent Offices). We hope to explore this issue in future research.
} 
stronger patent rights may have facilitated entry by specialized firms and contributed to vertical disintegration in this industry (Merges 1996; Arora and Fosfuri 1998). But these positive effects coincide with a process whereby firms amass vast patent portfolios simply as "bargaining chips," leading to "patent portfolio races." In principle, such racing behavior is not an inevitable outcome of strengthening patent rights in cumulative technological areas. If patent rights were strictly awarded to inventors of "non-obvious," "useful," and "novel" inventions, then it should become increasingly difficult to obtain a patent when a thicket of prior art exists, and the number of successful patent applications should fall. However, this is not what we observe in this industry.

Although our study highlights the multifaceted effects of strengthening patent rights on firms even within one cumulative technological setting, it raises a number of unresolved questions. What are the overall social welfare consequences associated with the type of "patent portfolio races" that we observe in this industry? Does this behavior simply represent the outcome of a non-cooperative strategic game and, therefore, an implicit "tax" on innovation? Or do these portfolios provide an important backdrop for exchanges of intellectual property and more tacit "know-how" that otherwise would not take place? Under what conditions do the social costs associated with "patent portfolio races" begin to outweigh their benefits? This study therefore underlines the importance of continuing theoretical and empirical research on the effects of strengthening patent rights in technological settings where innovation is inherently cumulative but firms also rely on mechanisms other than patents to appropriate returns to R\&D. 


\section{Table 1}

Sample Statistics

US Semiconductor Sample before Cleaning

1525 Observations (110 Firms) 1965-1997

\begin{tabular}{|l|cc|ccc|cc|}
\hline Variable Name & Mean & S.D. & Median & First Q & Third Q & Min & Max \\
\hline Patent Applications & 11.10 & 43.68 & 1 & 0 & 4 & 0 & 565 \\
R\&D (\$M 1992)* & 4.77 & 2.14 & 4.63 & 0.55 & 15.05 & 0 & 2116.8 \\
Employment (1000s)* & 0.645 & 1.77 & 0.551 & 0.192 & 1.797 & 0 & 89.9 \\
P\&E per employee* & 21.7 & 0.84 & 24.0 & 13.10 & 43.6 & 0.8 & 252.8 \\
$\begin{array}{l}\text { (\$1000 1992) } \\
\text { Age of Firm }\end{array}$ & 24.4 & 12.9 & 22 & 13 & 35 & 3 & 60 \\
D(R\&D=0) & 0.069 & $(\mathrm{~N}=105)$ & & & & & \\
D(entered after 1982) & 0.298 & $(\mathrm{~N}=454)$ & & & & & \\
D(design firms) & 0.199 & $(\mathrm{~N}=303)$ & & & & & \\
\hline
\end{tabular}

\section{US Semiconductor Sample Used in Regressions 946 Observations (95 Firms) 1979-1995}

\begin{tabular}{|l|cc|ccc|cc|}
\hline Variable Name & Mean & S.D. & Median & First Q & Third Q & Min & Max \\
\hline Patent Applications & 17.62 & 64.86 & 1 & 0 & 6 & 0 & 768 \\
R\&D (\$M 1992)* & 4.98 & 2.13 & 5.75 & 0.74 & 16.83 & 0 & 1212.6 \\
Employment (1000s) & 0.537 & 1.74 & 0.491 & 0.16 & 1.46 & 0 & 89.9 \\
P\&E per employee* & 24.4 & 0.91 & 26.8 & 13.2 & 46.1 & 0.4 & 247.1 \\
$\begin{array}{l}\text { (\$1000 1992) } \\
\text { Age of Firm in 1995 }\end{array}$ & 24.0 & 11.7 & 24 & 14 & 33 & 3 & 59 \\
D(R\&D=0) & 0.042 & $(\mathrm{~N}=40)$ & & & & & \\
D(entered after 1982) & 0.196 & $(\mathrm{~N}=185)$ & & & & & \\
D(design firm) & 0.203 & $(\mathrm{~N}=192)$ & & & & & \\
\hline
\end{tabular}

*Geometric means are shown for these variables, along with the standard deviation of the log.

The intersection of design firms and post-1982 entry contains 103 observations. 
Table 2

\section{Patenting Propensity Estimates \\ US Semiconductor Firms 1979-1995 \\ 946 Observations}

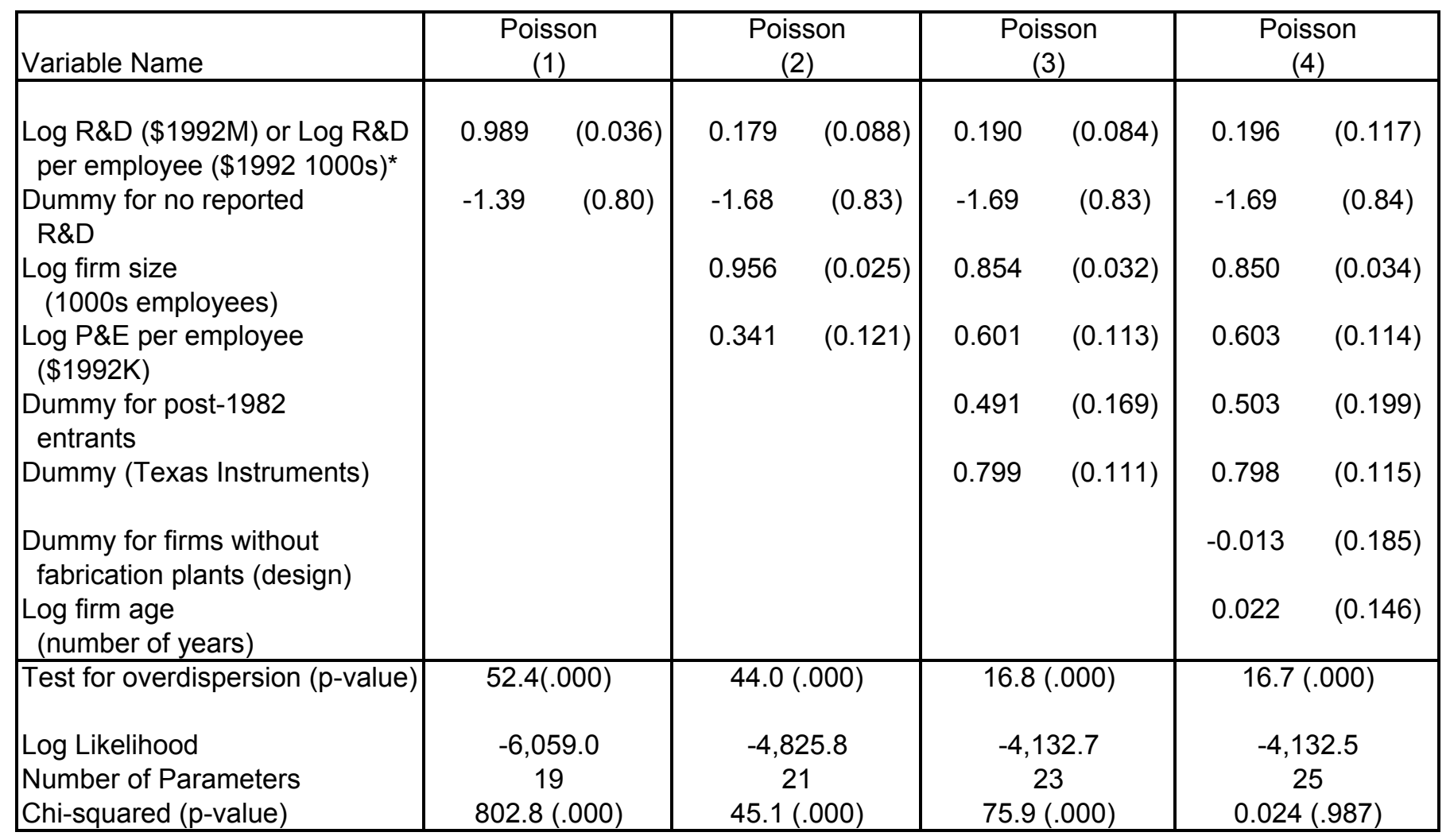

*Log R\&D in column (1); Log R\&D per employee in the other columns.

Heteroskedastic-consistent standard errors are shown in parentheses.

The method of estimation is maximum likelihood for the Poisson model (which is generalized ML for the exponential mean function).

The chi-squared is a Wald test for the specification in the column to the left versus the current column.

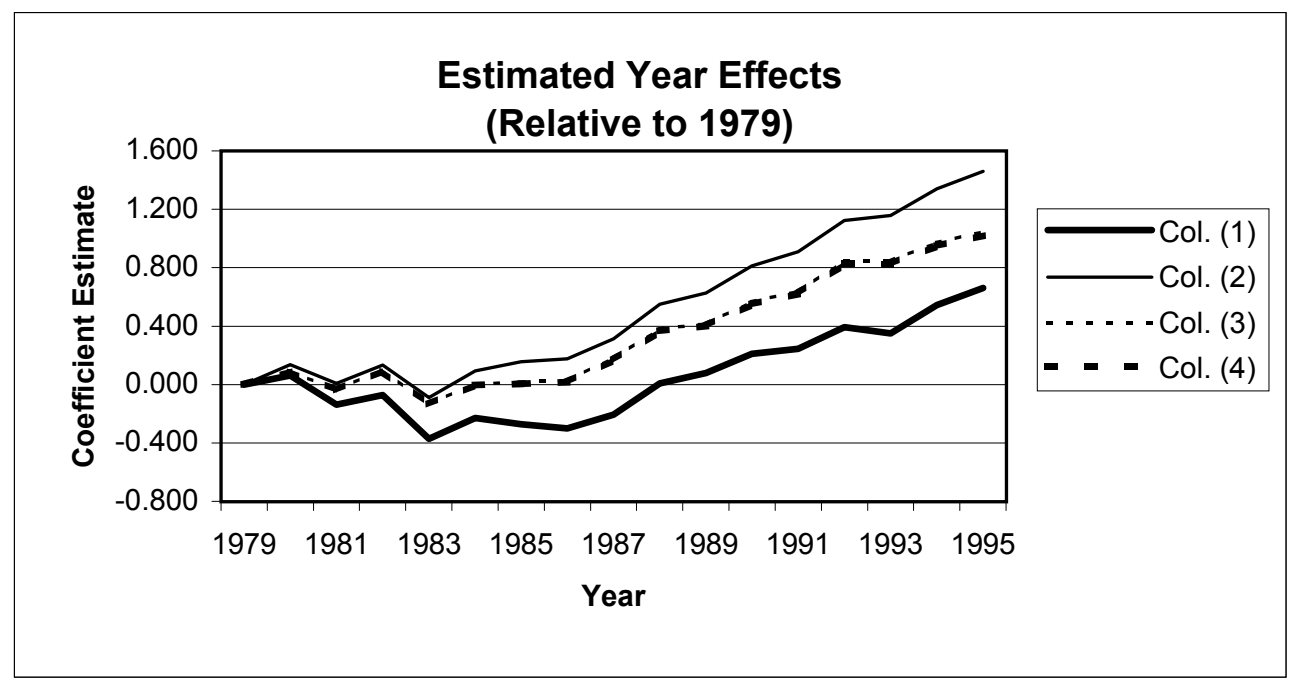




\section{Table 3: Changes in the Determinants of Patenting US Semiconductor Firms, Pre-1984 Incumbents 5-year Time Intervals}

$Y=$ Number of Successful Patent Applications per firm per year

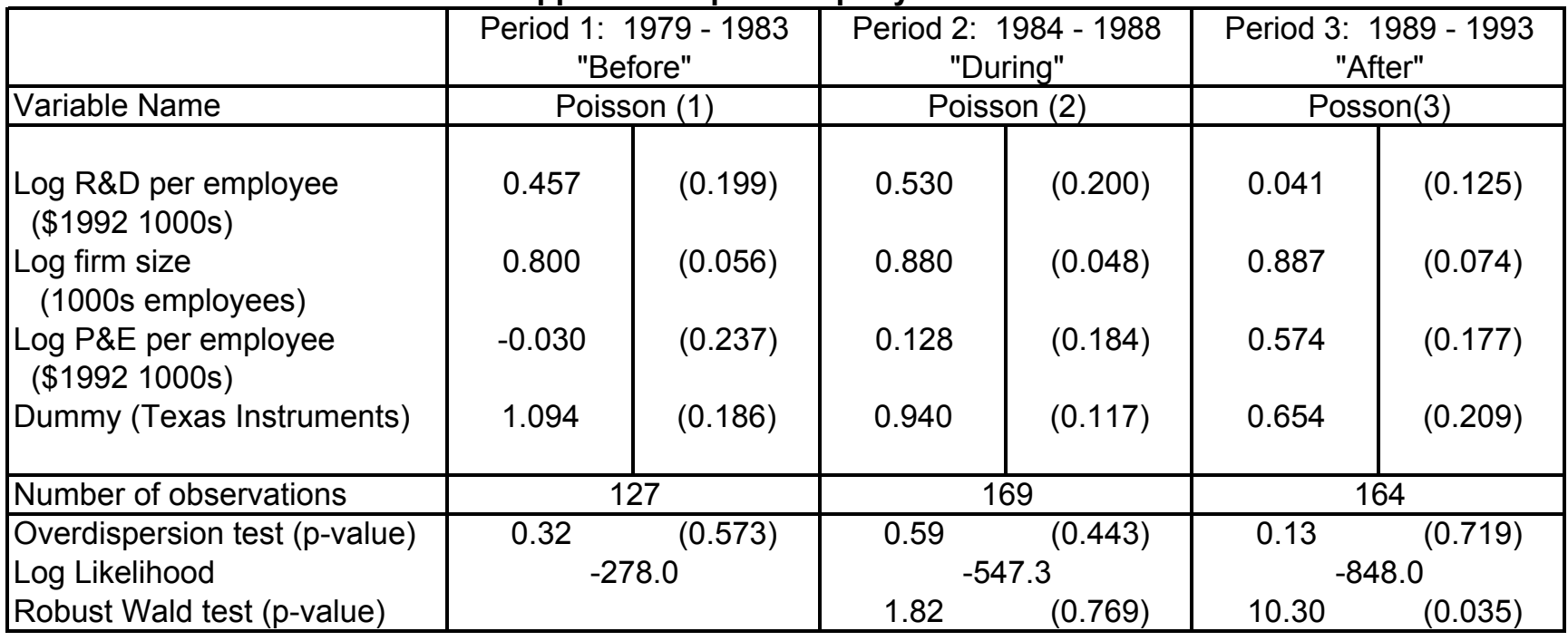

$$
{ }^{* *} p<.01 \quad{ }^{*} p<.05
$$

Notes: 1. Sample includes 34 firms publicly traded before 1984 and for which data were available in all 3 periods.

2. The results were largely unchanged by including (a) incumbents that exit in periods 2 or 3 or (b) design firm dummies.

3. All estimates include a full set of year dummies. Heteroskedastic-consistent standard errors are shown in parentheses.

4. 14 observations for firms that did not perform R\&D have been deleted.

5. The Wald tests are for equality of column 2 or 3 slope coefficients with those of column 1 . 
Table 4

Patenting Propensity Estimates

US Semiconductor Firms 1979-1995

95 Firms (946 Observations)

\begin{tabular}{|c|c|c|c|c|c|c|c|c|}
\hline Variable Name & \multicolumn{2}{|c|}{ (1) } & \multicolumn{2}{|c|}{$(2)$} & \multicolumn{2}{|c|}{ (3) } & \multicolumn{2}{|c|}{ (4) } \\
\hline \multirow[b]{2}{*}{ Intercept } & \multicolumn{8}{|c|}{ Manufacturing Firm Coefficients } \\
\hline & \multicolumn{2}{|c|}{ year dummies } & \multicolumn{2}{|c|}{ year dummies } & \multicolumn{2}{|c|}{ year dummies } & \multicolumn{2}{|c|}{ year dummies } \\
\hline $\begin{array}{l}\text { Log R\&D per employee } \\
\text { (\$1992 1000s) }\end{array}$ & 0.192 & $(0.104)$ & 0.169 & $(0.112)$ & 0.192 & $(0.105)$ & 0.168 & $(0.117)$ \\
\hline $\begin{array}{l}\text { Dummy for no reported } \\
\text { R\&D }\end{array}$ & -1.69 & $(0.84)$ & -1.81 & $(0.84)$ & -1.69 & $(0.84)$ & -1.81 & $(0.84)$ \\
\hline $\begin{array}{l}\text { Log firm size } \\
\text { (1000s employees) }\end{array}$ & 0.854 & $(0.033)$ & 0.830 & $(0.035)$ & 0.852 & $(0.033)$ & 0.830 & $(0.035)$ \\
\hline $\begin{array}{l}\text { Log P\&E per employee } \\
\text { (\$1992 1000s) }\end{array}$ & 0.599 & $(0.123)$ & 0.635 & $(0.136)$ & 0.606 & $(0.126)$ & 0.639 & $(0.137)$ \\
\hline $\begin{array}{l}\text { Dummy for post-1982 } \\
\text { entrants }\end{array}$ & 0.492 & $(0.173)$ & 0.124 & $(0.254)$ & 0.477 & $(0.176)$ & 0.129 & $(0.254)$ \\
\hline \multirow[t]{2}{*}{ Dummy (Texas Instruments) } & 0.800 & $(0.114)$ & 0.833 & $(0.122)$ & 0.804 & $(0.114)$ & 0.833 & $(0.122)$ \\
\hline & \multicolumn{8}{|c|}{ Design Firm Coefficients } \\
\hline Intercept & \multicolumn{2}{|c|}{$-0.012 \quad(0.183)$} & 0.051 & $(0.844)$ & \multicolumn{2}{|c|}{ year dummies } & \multicolumn{2}{|c|}{ year dummies } \\
\hline $\begin{array}{l}\text { Log R\&D per employee } \\
\text { (\$1992 1000s) }\end{array}$ & \multicolumn{2}{|l|}{ same } & 0.171 & $(0.240)$ & \multicolumn{2}{|l|}{ same } & 0.265 & $(0.231)$ \\
\hline $\begin{array}{l}\text { Log firm size } \\
\text { (1000s employees) }\end{array}$ & \multicolumn{2}{|l|}{ same } & 0.881 & $(0.068)$ & \multicolumn{2}{|l|}{ same } & 0.896 & $(0.065)$ \\
\hline $\begin{array}{l}\text { Log P\&E per employee } \\
\text { (\$1992 1000s) }\end{array}$ & \multirow{2}{*}{\multicolumn{2}{|c|}{ same }} & 0.399 & $(0.149)$ & \multicolumn{2}{|l|}{ same } & 0.301 & $(0.153)$ \\
\hline $\begin{array}{l}\text { Dummy for post-1982 } \\
\text { entrants }\end{array}$ & & & 1.592 & $(0.276)$ & \multicolumn{2}{|l|}{ same } & 1.600 & $(0.274)$ \\
\hline Test for overdispersion ( $p$-value) & \multirow{3}{*}{\multicolumn{2}{|c|}{$\begin{array}{c}16.8(.000) \\
-4,132.7 \\
24\end{array}$}} & \multirow{3}{*}{\multicolumn{2}{|c|}{$\begin{array}{c}16.8(.000) \\
-3,989.5 \\
28 \\
19.7(.000)\end{array}$}} & \multirow{3}{*}{\multicolumn{2}{|c|}{$\begin{array}{c}17.1(.000) \\
-4,108.8 \\
40 \\
57.2(.000)\end{array}$}} & \multirow{3}{*}{\multicolumn{2}{|c|}{$\begin{array}{c}17.1(.000) \\
-3,968.2 \\
44 \\
20.9(.000) \\
\end{array}$}} \\
\hline Log Likelihood & & & & & & & & \\
\hline Number of Parameters & & & & & & & & \\
\hline
\end{tabular}

See notes to Table 2. Chi-squared tests are col. 2 vs col. 1 , col. 3 vs col. 1 , col. 4 vs col. 3. 


\section{Figure 1 \\ Patents per Million R\&D Dollars \\ U.S. Manufacturing}

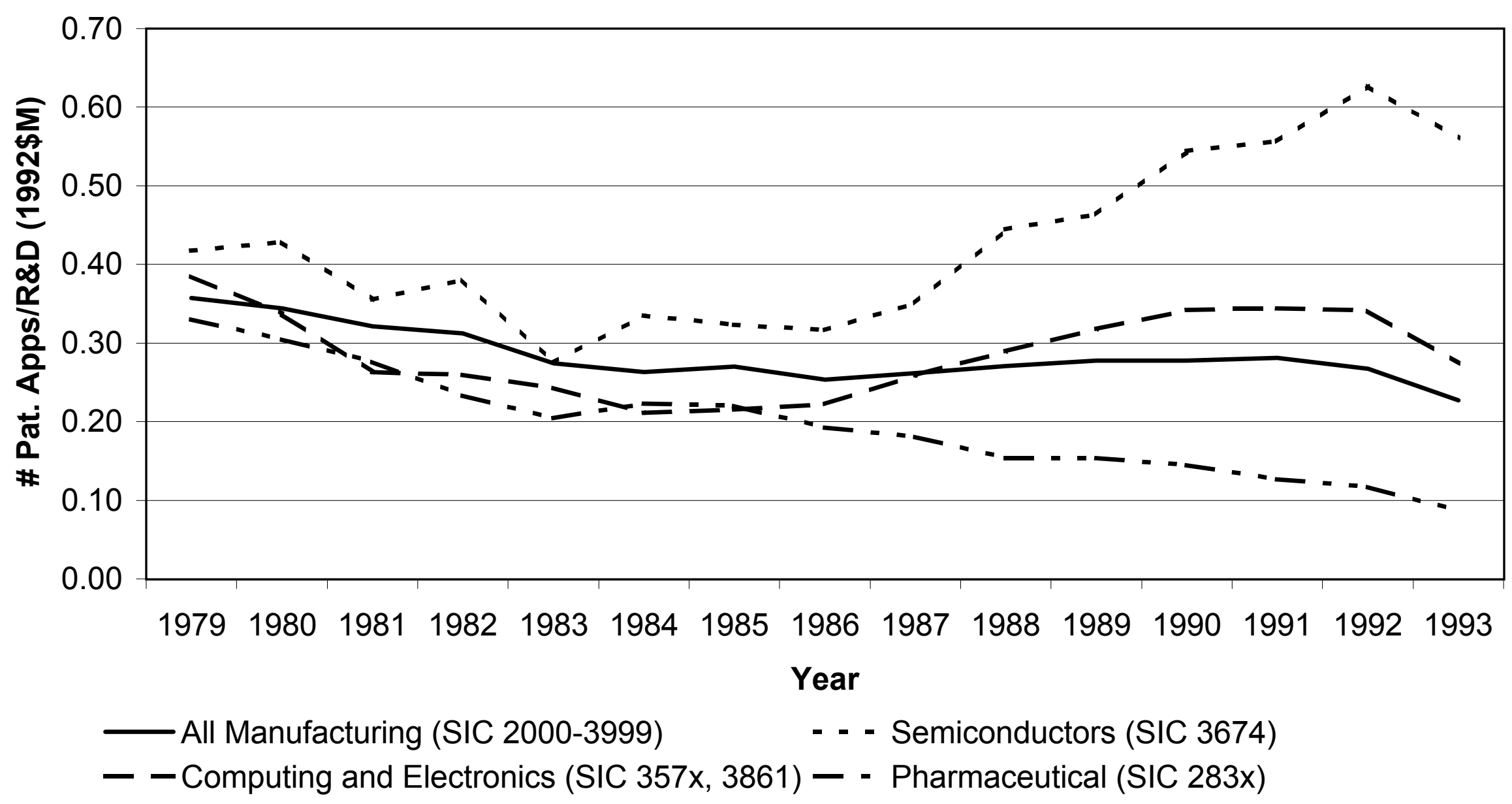




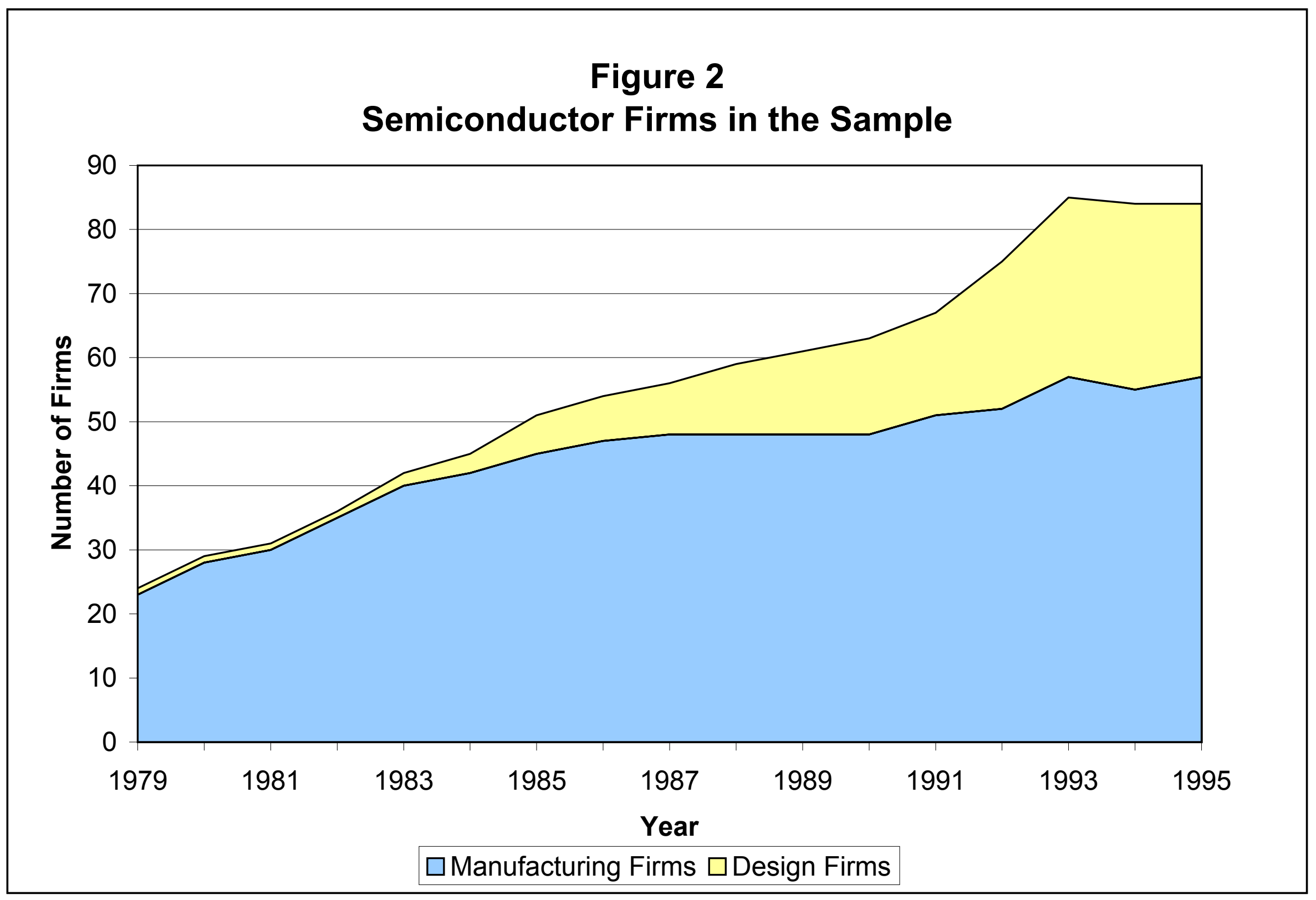


Figure 3

Patents per Million R\&D Dollars

Semiconductor Firms

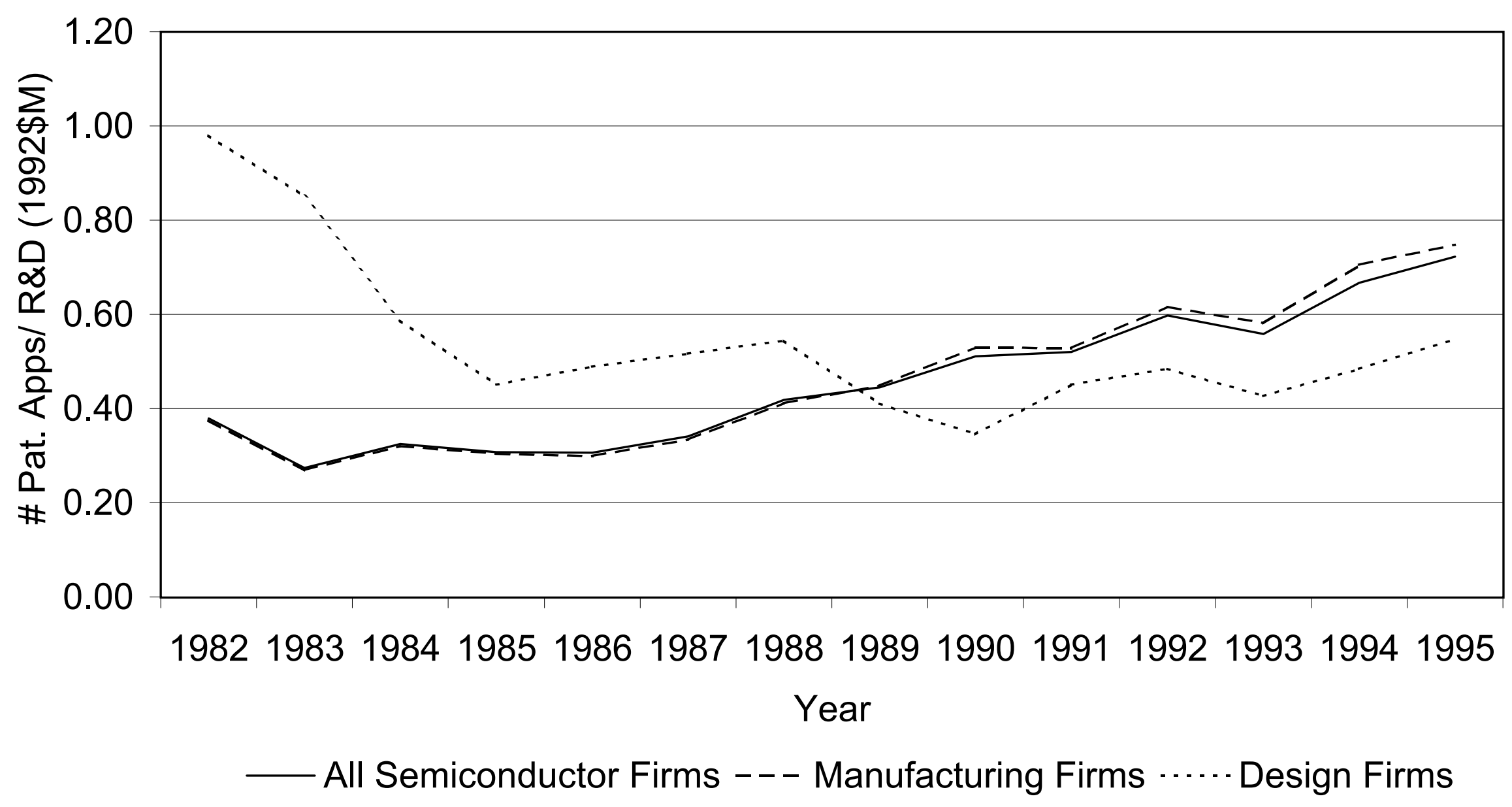


Figure 4

Cites per Patent (Corrected for Lag Truncation)

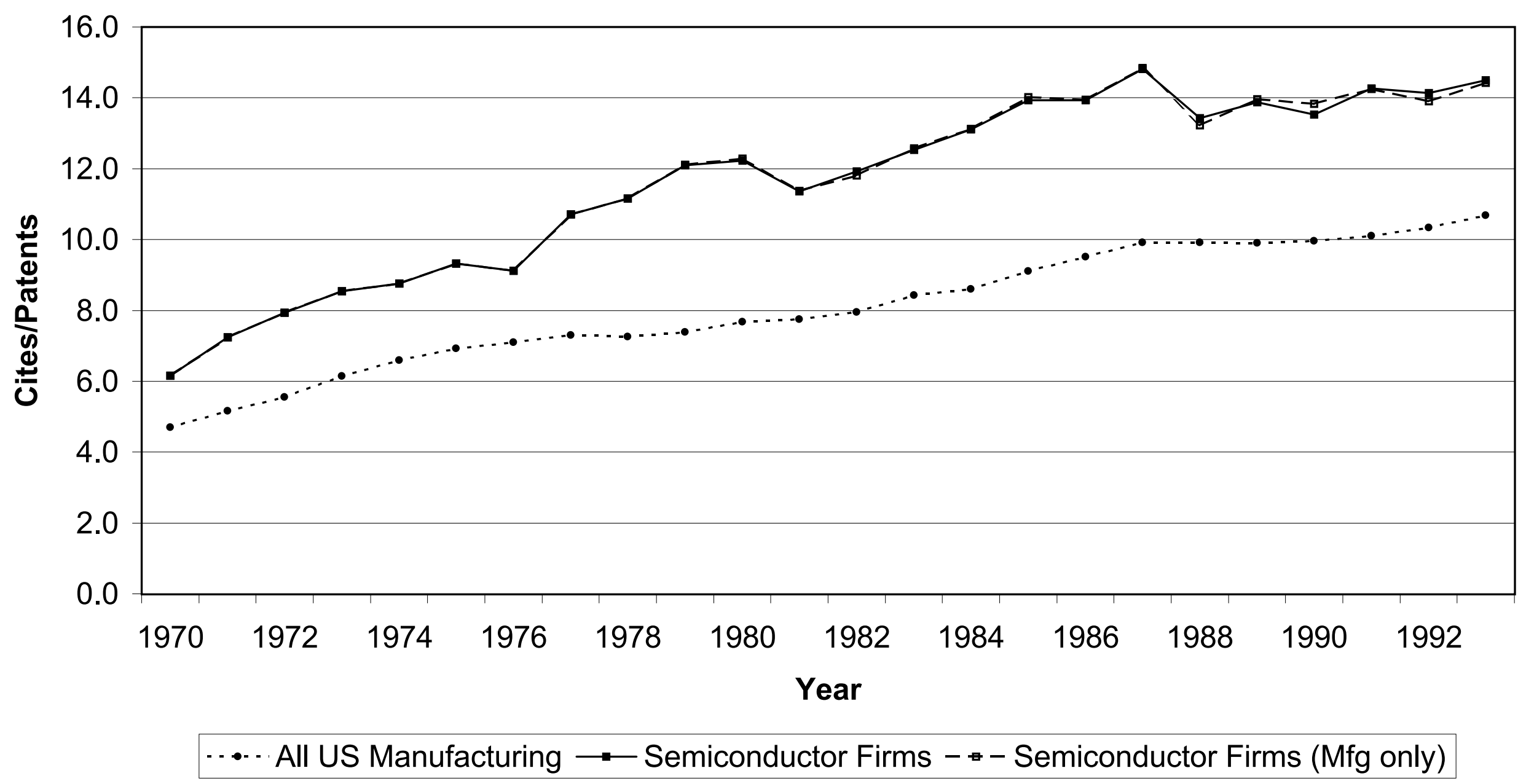


Figure 5

Semiconductor Cites per Patent

Relative to All Manufacturing

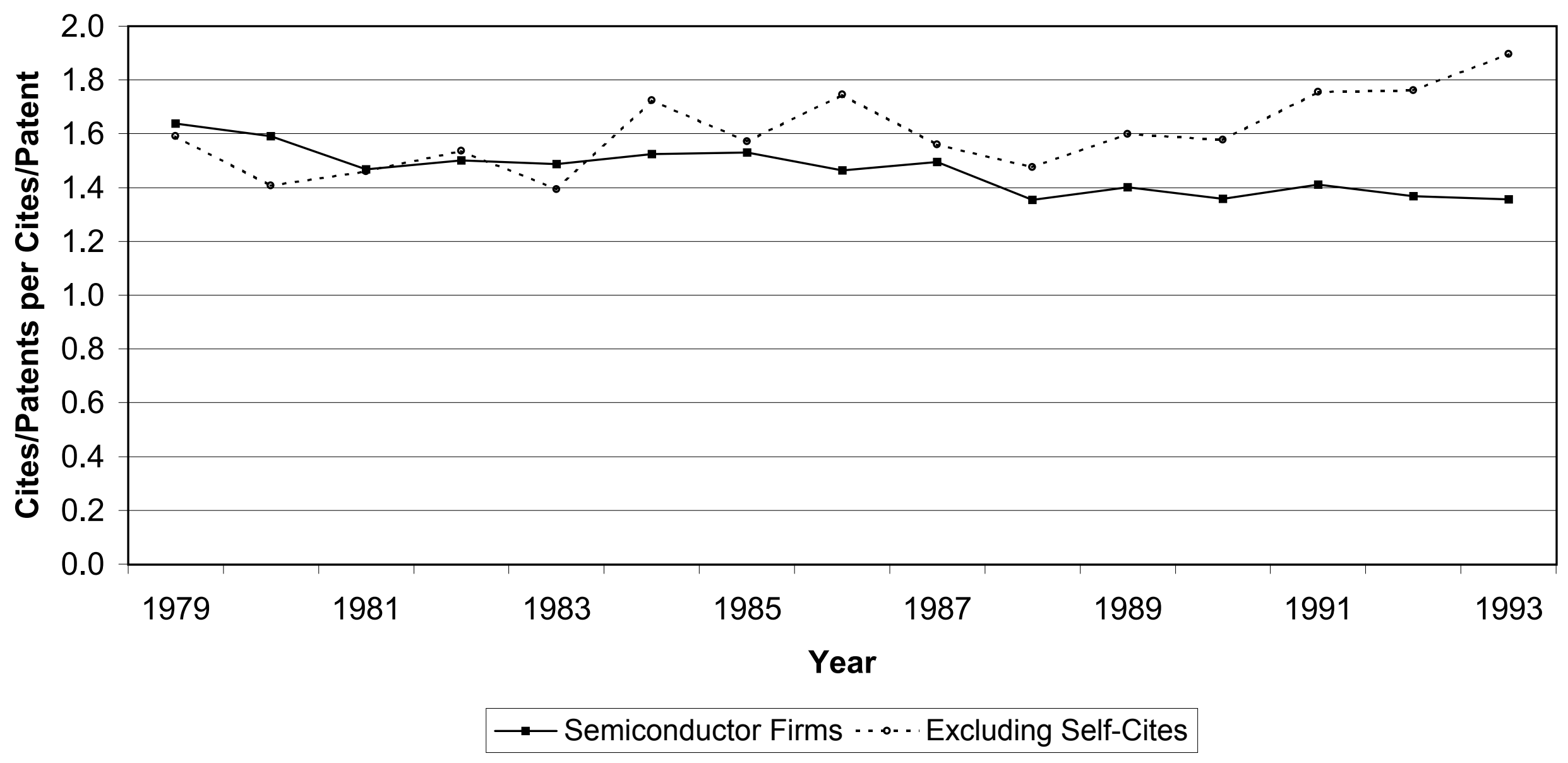


Figure 6

Number of Claims per Patent

Semiconductor Firms Relative to All Manufacturing

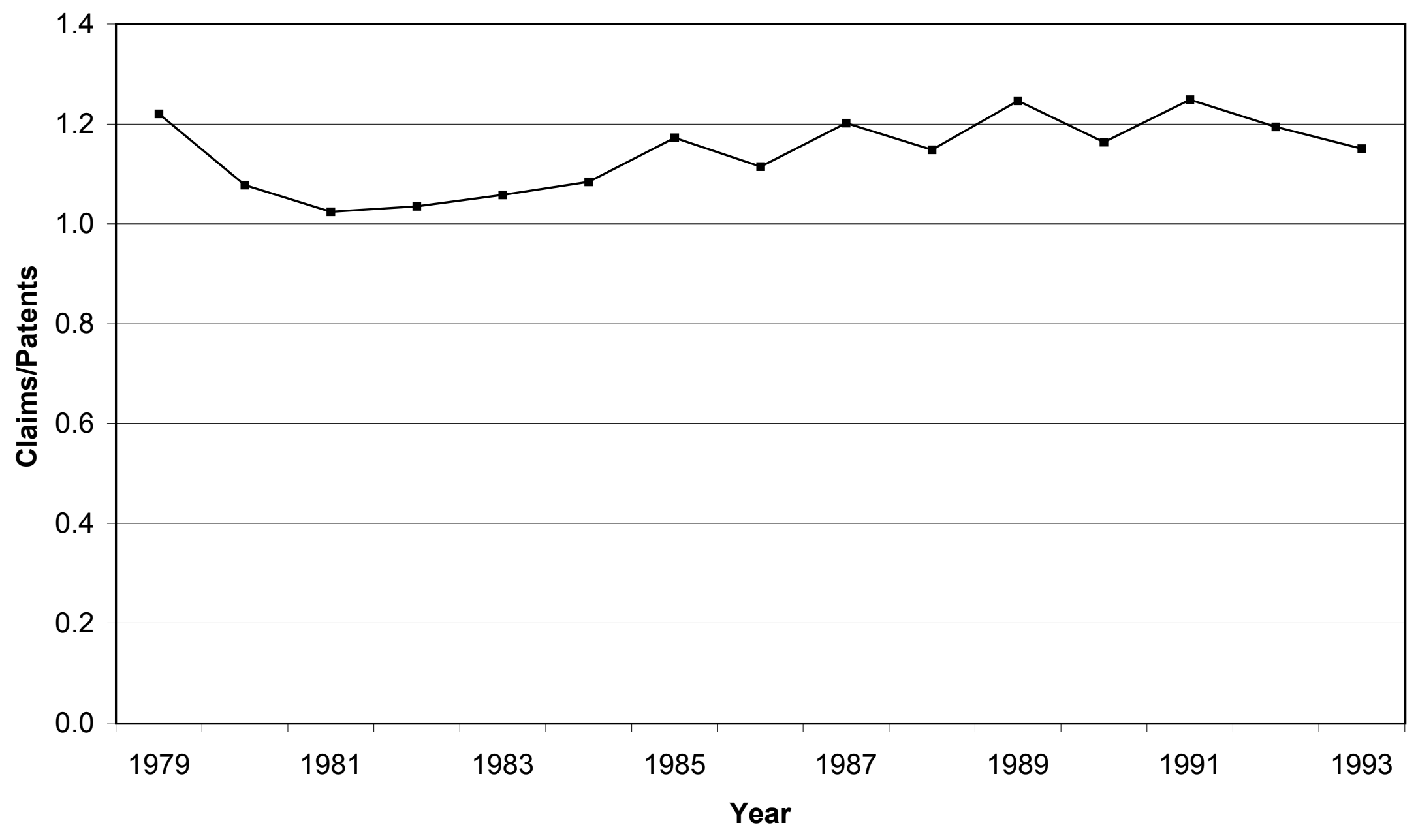




\section{References}

Adelman, M.J. (1987). "The New World of Patents Created by the Court of Appeals for the Federal Circuit," Journal of Law Reform 20 (4): 979-1007.

Arora, A. (1995). "Licensing Tacit Knowledge: Intellectual Property Rights and the Market for Know-How," Economics of Innovation and New Technology 4: 41-59.

Arora, A. and A. Fosfuri (1998). "Licensing in the Chemical Industry," conference paper, Intellectual Property and Industry Competitive Standards, Stanford University, April.

Arora, A. and A. Gambardella (1994). "The Changing Technology of Technological Change: General and Abstract Knowledge and the Division of Innovative Labour," Research Policy 23: 523-532.

Barton, J.H. and S.J. Parapatt (1998). "Patent Litigation and Its Relationship to Industry Structure and Competition in the Photographic Film and Camera Industry," conference paper, Intellectual Property and Industry Competitive Standards, Stanford University, April.

Bessen, J. and E. Maskin (2000). "Sequential Innovation, Patents, and Imitation," working paper no. 00-01, Department of Economics, Massachusetts Institute of Technology.

Blundell, R., R. Griffith, and F. Windmeijer (1997). "Individual Effects and Dynamics in Count Data Models," unpublished manuscript (August).

Cameron, A.C. and P.K. Trivedi (1998). Regression Analysis of Count Data (Cambridge, UK:

Cambridge University Press).

Cohen, W.M., R.R. Nelson, and J. Walsh (2000). "Protecting Their Intellectual Assets:

Appropriability Conditions and Why U.S. Manufacturing Firms Patent (or Not), Carnegie Mellon University working paper, January.

Gourieroux, C., A. Montfort, and A. Trognon (1984). "Pseudo Maximum Likelihood Methods: Applications to Poisson Models," Econometrica 52(3): 701-720.

Green, J.R and S. Scotchmer (1995). "On the division of profit in sequential innovation," Rand Journal of Economics, Spring 26(1): 20-33.

Grindley, P.C and D.J. Teece (1997). "Managing Intellectual Capital: Licensing and CrossLicensing in Semiconductors and Electronics," California Management Review 39(2): 1-34.

Griliches, Z. 1990. "Patent Statistics as Economic Indicators: A Survey," Journal of Economic Literature XXVIII: 1661-1707.

Griliches, Z., B.H. Hall, and A. Pakes (1991). "R\&D, Patents and Market Value Revisited: Is there a Second (Technological Opportunity) Factor?" Economics of Innovation and New Technology 1: 183-202.

Hall, B. H., and C. Cummins (1999). TSP Reference Manual, Version 4.5, Palo Alto, CA: TSP International. 
Hall, B. H., Z. Griliches, and J. A. Hausman (1986). "Patents and R\&D: Is There a Lag?," International Economic Review 27: 265-283.

Hall, B. H., A. Jaffe, and M. J. Trajtenberg (2000). "Market Value and Patent Citations: A First Look," Nuffield College, Oxford, UC Berkeley, Brandeis University, Tel Aviv University, and NBER Working Paper No. (forthcoming).

Ham, R.M., G.L. Linden, and M.M. Appleyard (1998). "The Evolving Role of Semiconductor Consortia in the United States and Japan," California Management Review 41: 137-163.

Harhoff, Dietmar, Francis Narin, F.M. Scherer, and Katrin Vopel (1999). "Citation Frequency and the Value of Patented Inventions," The Review of Economics and Statistics 81(3): 511-515.

Hausman, J. A., B. H. Hall, and Z. Griliches (1984). "Econometric Models for Count Data with an Application to the Patents-R\&D Relationship," Econometrica 52: 909-938.

Headley, W. (1998). "Rapporteur's Report: The Stanford Workshop on Intellectual Property and Industry Competitive Standards," Stanford Law and Technology Policy Center, Stanford University Law School (April 17-18).

Hunt, R.M. (1999). "Nonobviousness and the Incentive to Innovate: An Economic Analysis of Intellectual Property Reform," working paper no. 99-3, Economic Research Division, Federal Reserve Bank of Philadelphia.

Integrated Circuit Engineering Corporation (1995). Cost Effective IC Manufacturing 1995. (Scottsdale, AZ: Integrated Circuit Engineering Corporation).

Integrated Circuit Engineering Corporation (1976-98). Status: A Report on the Integrated Circuit Industry. (Scottsdale, AZ: Integrated Circuit Engineering Corporation).

Jaffe, A. (2000). "The U.S. Patent System in Transition: Policy Innovation and the Innovation Process," Research Policy 29: 531-557.

Jaffe, Adam and Manuel Trajtenberg (1996). "Flows of Knowledge from Universities and Federal Labs: Modeling the Flow of Patent Citations over Time and Across Institutional and Geographic Boundaries," Proceedings of the National Academy of Sciences 93: 12671-12677. (1999). "International Knowledge Flows: Evidence from Patent Citations," Economics of Innovation and New Technology 8: 105-136.

Jaffe, Adam, Manuel Trajtenberg and Michael Fogarty (2000). "The Meaning of Patent Citations: Report of the NBER/Case Western Reserve Survey of Patentees," National Bureau of Economic Research Working Paper No. 7631.

Kortum, S. and J. Lerner (1998). "Stronger Protection or Technological Revolution: What is Behind the Recent Surge in Patenting?," Carnegie-Rochester Conference Series on Public Policy 48: 247-304. 
Lanjouw, J.O. and J. Lerner (1996). "Preliminary Injunctive Relief: Theory and Evidence from Patent Litigation," Harvard Business School working paper no. 96-068, and NBER working paper no. 5689.

Lanjouw, J.O. and M. Schankerman (1999). "The Quality of Ideas: Measuring Innovation with Multiple Indicators,” NBER Working Paper No. W7345.

Lanjouw, J.O. and M. Schankerman (1997). "Stylized Facts of Patent Litigation: Value, Scope, and Ownership,” NBER Working Paper No. W6297.

Lerner, J. (1995). "Patenting in the Shadow of Competitors," Journal of Law and Economics, (October): 463-495.

Levin, R.C. (1982). “The Semiconductor Industry," in Richard R. Nelson, ed., Government and Technical Progress: A Cross-Industry Analysis (Pergamon Press, 1982).

Levin, R.C., A.K. Klevorick, R.R. Nelson, and S.G. Winter (1987). "Appropriating the Returns from Industrial Research and Development," Brookings Papers on Economic Activity (3): 783820 .

Macher, J., D.C. Mowery, and D. Hodges (1998). "Reversal of Fortune? The Recovery of the U.S. Semiconductor Industry," California Management Review 41(1): 107-136.

Mansfield, E. (1986). "Patents and Innovation: An Empirical Study," Management Science 32(2): 173-181.

Mazzoleni, R. and R.R. Nelson (1998). "Economic Theories about the Benefits and Costs of Patents" Journal of Economic Issues 32(4): 1031-1052.

Merges, R.P (1998). "Property Rights, Transactions, and the Value of Intangible Assets," working paper, Boalt School of Law, University of California, Berkeley.

Merges, R.P. (1997). Patent Law and Policy: Cases and Materials. Second edition. (Charlottesville, VA: The Mitchie Company).

Merges, R.P. (1996). Contracting into Liability Rules: Intellectual Property Rights and Collective Rights Organizations," California Law Review 84(5): 1293-1393.

Merges, R.P. and Nelson, R.R. (1990). "On the Complex Economics of Patent Scope," Columbia Law Review 90(4): 839-916.

Montalvo, J. G. (1997). "GMM Estimation of Count-Panel-Data Models with Fixed Effects and Predetermined Instruments," Journal of Business and Economic Statistics 15(1): 82-89.

Nies, H.W. (1993). "Ten Years of Patent Law Development Under the U.S. Court of Appeals for the Federal Circuit," IIC 24(6): 797-803.

O'Donoghue, T. (1998). "A patentability requirement for sequential innovation," Rand Journal of Economics, Winter 29(4): 654-679. 
O’Donoghue, T., S. Scotchmer, and J-F Thisse (1998). "Patent Breadth, Patent Life, and the Pace of Technological Progress," Journal of Economics and Management Strategy, Spring 7(1): 1-32.

Pakes, A., and Z. Griliches (1980). "Patents and R\&D at the Firm Level: A First Look," Economic Letters 5: 377-381.

Reinganum, J.F. (1989). "The Timing of Innovation: Research, Development, and Diffusion," in R. Schmalansee and R.D. Willig, eds., Handbook of Industrial Organization. (New York: NorthHolland).

Scherer, F.M., S.E. Herzstein, Jr., A.W. Dreyfoos, W.G. Whitney, O.J. Bachmann, C.P. Pesek, C.J. Scott, T.G. Kelly, and J.J. Galvin (1959). Patents and the Corporation: A Report on Industrial Technology Under Changing Public Policy, second edition (Boston, MA: Harvard University, Graduate School of Business Administration).

Scotchmer, S. (1996). "Protecting Early Innovators: Should Second-Generation Products Be Patentable?" Rand Journal of Economics 27: 322-331.

Scotchmer, S. (1991). "Standing on the Shoulders of Giants: Cumulative Innovation and the Patent Law," Journal of Economic Perspectives 5:29-41.

Scotchmer, S. and J. Green (1990). "Novelty and Disclosure in Patent Law," Rand Journal of Economics, Spring 21(1): 131-146.

Shinal, J. (1998). "IBM again tops technology rivals for most patents," The San Diego UnionTribune, 20 January.

Taylor, C.T. and Z. A. Silberston (1973). The Economic Impact of the Patent System: A Study of the British Experience (Cambridge, UK: University Press).

Teece, D.J. (1986). “Profiting from Technological Innovation,” Research Policy 15: 285-305.

US Patent and Trademark Office (USPTO) (1995), Technology Profile Report: Semiconductor Devices and Manufacture, 1/1969 - 12/1994 (Washington, D.C: U.S. Department of Commerce).

Von Hippel, E. (1988). The Sources of Innovation. (Oxford, U.K.: Oxford University Press).

Ziedonis, R. H. (2000). Firm Strategy and Patent Protection in the Semiconductor Industry, unpublished doctoral dissertation, Walter A. Haas School of Business, University of California, Berkeley. 


\section{Appendix A \\ Do Stronger Patents Induce More R\&D And/Or More Patents?}

This appendix sketches a simple model of $\mathrm{R} \& \mathrm{D}$ and patenting in order to understand the answers to two questions: 1) Do stronger patents induce more R\&D? 2) Do stronger patents induce more patenting per R\&D dollar? It is commonly assumed in the literature that the answer to the first question is yes, but the answer to the second is less obvious.

Assume that there are a continuous number of $\mathrm{R} \& \mathrm{D}$ projects available on a unit interval $[0, A]$ where the revenue (profit gross of $\mathrm{R} \& \mathrm{D}$ and patenting expenditure) is subject to diminishing returns:

$$
f_{a}(R)=a R^{\sigma} \quad \sigma<1 \text { and } a \in[0, A]
$$

In the absence of patenting, the firm chooses the level of $R \& D$ for each project using the usual first order condition for profit maximization:

$$
f_{a}^{\prime}(R)=a \sigma R^{\sigma-1}=1
$$

yielding

$$
R^{*}(a)=(a \sigma)^{-1 /(\sigma-1)}
$$

Having chosen the R\&D level for each project, the firm will perform all the projects with nonnegative profits, that is, all projects where

$$
a R^{* \sigma}>R^{*}
$$

In this Cobb-Douglas case, the condition does not bind, and all projects on $[0, A]$ will be performed (some at a very small scale). The profit from each project is equal to

$$
\Pi(a)=R^{*}(a) \frac{1-\sigma}{\sigma}
$$

Total R\&D expenditure is obtained by integrating $R^{*}$ over the interval:

$$
\int_{0}^{A} R^{*}(a) d a=\int_{0}^{A}(a \sigma)^{-1 /(\sigma-1)} d a=\sigma^{-1 /(\sigma-1)} \frac{\sigma-2}{\sigma-1} A^{(\sigma-2) /(\sigma-1)}
$$

Now suppose that patents are introduced. They have two features: first, they increase the scale of the profit on each R\&D project from $a$ to $\widetilde{a}=\phi a$ where $\phi>1$. Therefore the range of projects available is now the interval $[0, \phi A]$. Second, to obtain a patent on the outcome of a project, a firm must incur a fixed cost $c$. These two facts mean that the firm will now undertake more projects, some of which will be patented, and some of which will not be patented (because the profits will not cover the fixed cost of patenting). If the output of a project is patented, the optimal R\&D level is now given by

$$
R^{*}(\widetilde{a})=(\phi a \sigma)^{-1 /(\sigma-1)}
$$


which is a higher level of R\&D for the same project than when patents were not available. The profit for this project is now

$$
\Pi(\widetilde{a})=R^{*}(\widetilde{a}) \frac{1-\sigma}{\sigma}-c
$$

The decision to seek a patent on the output of the project depends on a comparison between the profit without a patent and the profit with a patent:

$$
\begin{aligned}
R^{*}(\widetilde{a}) \frac{1-\sigma}{\sigma}-c & >R^{*}(a) \frac{1-\sigma}{\sigma} \\
R^{*}(\widetilde{a})-R^{*}(a) & >\frac{\sigma}{1-\sigma} c
\end{aligned}
$$

Equation (1) implicitly defines a value $a^{*}$ for R\&D projects above which the outcomes will always be patented and below which it is not worth applying for a patent:

$$
a^{*}=\sigma^{-\sigma}\left(\frac{c}{1-\sigma}\right)^{1-\sigma}\left(\phi^{1 /(1-\sigma)}-1\right)^{\sigma-1}
$$

Under the assumptions of diminishing returns $(0<\sigma<1)$, higher returns with a patent than without $(\phi>1)$, and positive costs of a patent $(c>0)$, this expression is positive, so in general some innovations will be patented and some will not. However, if the costs of patenting are very large ( $c$ large), or the benefits very small ( $\phi$ close to unity), or returns do not diminish very quickly ( $\sigma$ close to unity), it is possible that $a^{*}$ will be outside the interval over which projects are available, and no patents will be taken out. In most realistic cases the range $[0, A]$ will be large enough to rule out this possibility.

\section{How does R\&D vary with patent strength?}

The preceding simple model demonstrates that when patents are available but costly, firms will do two sets of projects, one for which they will not seek patents (because they are too small and patents are too costly), and one set for which they will seek patents. The total R\&D budget $\bar{R}(\phi)$ is the integral of $\mathrm{R} \& \mathrm{D}$ spending for the projects on $\left[0, a^{*}\right]$ plus the integral for $\mathrm{R} \& \mathrm{D}$ spending for the projects on $\left[\phi a^{*}, \phi A\right]$ :

$$
\bar{R}(\phi)=\sigma^{-1 /(\sigma-1)} \frac{\sigma-2}{\sigma-1}\left(a^{*(\sigma-2) /(\sigma-1)}+\phi^{-1 /(\sigma-1)}\left[A^{(\sigma-2) /(\sigma-1)}-a^{*(\sigma-2) /(\sigma-1)}\right]\right)
$$

This quantity is clearly larger than R\&D spending when there are no patents. It is also possible to show that this quantity is an increasing function of $\phi$, so that stronger patents mean a higher R\&D budget. This is not a surprise, because stronger patents were defined in terms of more output per R\&D dollar. 


\section{How does patenting vary with patent strength?}

We are now in a position to compare patenting rates for different levels of patent protection. The parameter $\phi$ is a proxy for the strength of the patents taken out, with higher $\phi s$ corresponding to stronger patents, and therefore higher returns to a given $R \& D$ project. The number of patents is the width of the interval $\left[\phi a^{*}, \phi A\right]$, which increases as $\phi$ increases:

$$
\frac{d\left[\phi\left(A-a^{*}\right)\right]}{d \phi}=\left(A-a^{*}\right)-\phi \frac{d a^{*}}{d \phi}
$$

where

$$
\frac{d a^{*}}{d \phi}=-a^{*}\left(\phi^{1 /(1-\sigma)}-1\right)^{-1} \phi^{\sigma /(1-\sigma)}<0
$$

so that

$$
\frac{\text { dpatents }}{d \phi}=A+a^{*}\left(\phi^{1 /(1-\sigma)}-1\right)^{-1}
$$

Clearly the second derivative of this expression is negative, so the conclusion is that when each $\mathrm{R} \& \mathrm{D}$ project yields a single patentable innovation, stronger patent rights imply that more patents will be taken out, but at a diminishing rate.

\section{How does patenting per R\&D dollar vary with patent strength?}

Rather than compute this analytically, we simulated the model for a variety of choices for $c(0.05$ and 0.10 ), $\sigma$ (from 0.1 to 0.9 ), and $\phi$ (from 1 to 2 ). The figure shows the number of patents per $\mathrm{R} \& \mathrm{D}$ dollar as a function of patent strength $\phi$ for various choices of $\sigma$ and for a patent cost of 0.1 , which is about 10 percent of the R\&D cost per patent when $\sigma=0.5$, and about 1 percent when $\sigma=0.3$. Although this is relatively high, it may not be unrealistic as a measure of total management time and effort associated with the patenting of innovations. In any case, our key result is not affected by the choice of $c$, although it does affect the region over which the firms patent slightly.

The message in this figure is fairly clear: using the assumption of a continuum of R\&D projects with one patent possible per project, and diminishing returns to $\mathrm{R} \& \mathrm{D}$, the effect of stronger patents is to reduce the patent yield per REDD dollar over most of the range of $\phi$. Based on Mansfield's and Scherer's work on imitation cost, the relevant $\phi$ values seem likely to be in the range of 1.2-1.7 or so, where the curve is relatively flat. The result does not seem to be particularly sensitive to the range of $a$. 


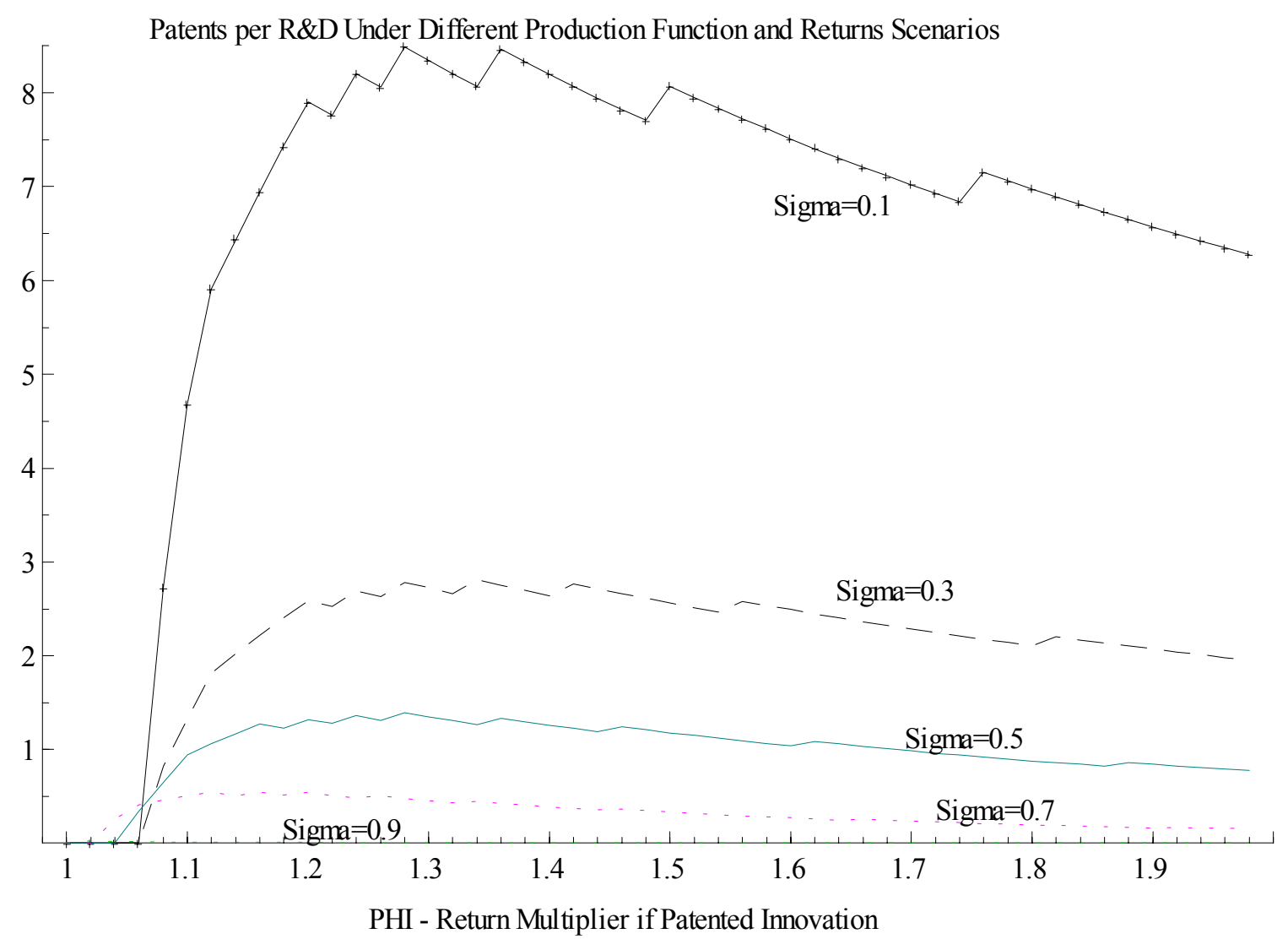

Figure 1: 


\section{Appendix B: Firms Included in Sample}

The tables in this appendix summarize the types of semiconductor firms included in our interview sample (Table B.1) and describe the sample firms included in our regressions (Table B.2).

Table B.1: Description of Firms in Interview Sample

\begin{tabular}{|c|c|c|c|c|}
\hline $\begin{array}{c}\text { Type of Firm } \\
\text { \# in sample) }\end{array}$ & Description & $\begin{array}{c}\mathbf{1 9 9 6} \\
\text { Sales } \\
\text { (in \$m) }\end{array}$ & $\begin{array}{c}\text { US Patent } \\
\text { Portfolio (\# } \\
\text { patents issued, } \\
1975-96)\end{array}$ & $\begin{array}{c}\text { Growth in US } \\
\text { patent propensity, } \\
\text { 1982-94 } \\
\text { (US pat apps/1992 } \\
\text { \$m R\&D) }\end{array}$ \\
\hline $\begin{array}{c}\text { Manufacturer } \\
(4)\end{array}$ & $\begin{array}{c}\text { Designs } \\
\text { semiconductors, } \\
\text { and manufactures } \\
\text { majority of } \\
\text { products in-house }\end{array}$ & $\begin{array}{c}\$ 1,200- \\
\$ 20,000\end{array}$ & $340-6500$ & $100 \%-300 \%$ \\
\hline $\begin{array}{c}\text { Design Firm } \\
(3)\end{array}$ & $\begin{array}{c}\text { Designs } \\
\text { semiconductors, } \\
\text { but contracts out } \\
\text { the manufacture of } \\
\text { products to other } \\
\text { firms }\end{array}$ & $\$ 30-\$ 500$ & $20-110$ & $-50 \%-233 \%$ \\
\hline
\end{tabular}


Table B.2

Sample of US Semiconductor Firms used in Regressions

\begin{tabular}{|c|c|c|c|c|c|c|c|}
\hline CUSIP & Name of Firm & $\begin{array}{c}\text { First year } \\
\text { of data }\end{array}$ & $\begin{array}{c}\text { Last year } \\
\text { of data }\end{array}$ & \begin{tabular}{|c|} 
Sales in \\
$1994(\$ M)$ \\
\end{tabular} & $\begin{array}{c}\text { R\&D in } \\
1994(\$ M)\end{array}$ & $\begin{array}{l}\text { Granted } 1994 \\
\text { Patent Apps. }\end{array}$ & $\begin{array}{c}\text { Total Patents } \\
\text { thru } 1996 \\
\end{array}$ \\
\hline 882508 & TEXAS INSTRUMENTS INC & 1965 & 1997 & 10315.0 & 689.00 & 565 & 7433 \\
\hline 637640 & NATIONAL SEMICONDUCTOR CORP & 1967 & 1997 & 2379.4 & 283.10 & 190 & 1545 \\
\hline 458140 & INTEL CORP & 1973 & 1997 & 11521.0 & 1111.00 & 311 & 1365 \\
\hline 007903 & ADVANCED MICRO DEVICES & 1973 & 1997 & 2134.7 & 279.98 & 125 & 1082 \\
\hline 595112 & MICRON TECHNOLOGY INC & 1976 & 1997 & 1628.6 & 83.40 & 74 & 698 \\
\hline 918270 & VLSI TECHNOLOGY INC & 1982 & 1997 & 587.1 & 79.59 & 75 & 420 \\
\hline 032654 & ANALOG DEVICES & 1970 & 1997 & 773.5 & 106.87 & 63 & 377 \\
\hline 502161 & LSI LOGIC CORP & 1982 & 1997 & 901.8 & 98.98 & 74 & 302 \\
\hline 460254 & INTL RECTIFIER CORP & 1965 & 1997 & 328.9 & 16.38 & 13 & 169 \\
\hline 235204 & DALLAS SEMICONDUCTOR CORP & 1984 & 1997 & 181.4 & 22.65 & 13 & 165 \\
\hline 122574 & BURR-BROWN CORP & 1975 & 1997 & 194.2 & 21.85 & 1 & 141 \\
\hline 827079 & SILICONIX INC & 1975 & 1997 & 196.5 & 15.78 & 16 & 114 \\
\hline 983919 & XILINX INC & 1984 & 1997 & 355.1 & 45.32 & 32 & 96 \\
\hline 020753 & ALPHA INDS & 1967 & 1997 & 78.3 & 3.26 & 2 & 91 \\
\hline 021441 & ALTERA CORP & 1984 & 1997 & 198.8 & 45.99 & 19 & 91 \\
\hline 989524 & ZILOG INC & 1972 & 1997 & 223.3 & 23.05 & 11 & 89 \\
\hline 535678 & LINEAR TECHNOLOGY CORP & 1976 & 1997 & 200.5 & 18.39 & 7 & 80 \\
\hline 232806 & CYPRESS SEMICONDUCTOR CORP & 1984 & 1997 & 406.4 & 53.19 & 25 & 75 \\
\hline 458118 & INTEGRATED DEVICE TECH INC & 1982 & 1997 & 422.2 & 78.38 & 13 & 73 \\
\hline 170021 & CHIPS \& TECHNOLOGIES INC & 1974 & 1997 & 73.4 & 11.79 & 4 & 67 \\
\hline 913283 & UNITRODE CORP & 1965 & 1997 & 97.1 & 9.43 & 7 & 64 \\
\hline 114577 & BROOKTREE CORP & 1984 & 1995 & 109.0 & 26.13 & 3 & 51 \\
\hline 049513 & ATMEL CORP & 1987 & 1997 & 375.1 & 43.03 & 8 & 48 \\
\hline 300645 & EXAR CORP & 1974 & 1997 & 159.5 & 14.38 & 3 & 40 \\
\hline $89674 \mathrm{~K}$ & TRIQUINT SEMICONDUCTOR INC & 1984 & 1997 & 29.2 & 9.94 & 0 & 39 \\
\hline 232815 & CYRIX CORP & 1989 & 1996 & 246.1 & 24.75 & 10 & 38 \\
\hline 518415 & LATTICE SEMICONDUCTOR CORP & 1985 & 1997 & 144.1 & 22.86 & 1 & 34 \\
\hline $69344 \mathrm{~F}$ & SIERRA SEMICONDUCTOR CORP & 1986 & 1997 & 108.6 & 28.62 & 16 & 33 \\
\hline 984903 & XICOR INC & 1979 & 1997 & 103.4 & 14.09 & 1 & 32 \\
\hline 413136 & HARMON INDUSTRIES INC & 1974 & 1997 & 119.7 & 4.56 & 3 & 31 \\
\hline 103025 & BOWMAR INSTRUMENT CORP & 1971 & 1997 & 27.8 & 0.59 & 2 & 31 \\
\hline $57772 \mathrm{~K}$ & MAXIM INTEGRATED PRODUCTS & 1985 & 1997 & 153.9 & 22.56 & 8 & 30 \\
\hline 595017 & MICROCHIP TECHNOLOGY INC & 1987 & 1997 & 208.0 & 20.75 & 8 & 25 \\
\hline 815779 & SEEQ TECHNOLOGY INC & 1981 & 1997 & 21.5 & 3.28 & 1 & 24 \\
\hline 751907 & RAMTRON INTERNATIONAL CORP & 1989 & 1997 & 20.4 & 16.45 & 12 & 23 \\
\hline 527295 & LEVEL ONE COMMUNICATIONS INC & 1989 & 1997 & 46.8 & 9.96 & 4 & 22 \\
\hline 834256 & SOLITRON DEVICES INC & 1973 & 1996 & 6.3 & 0.00 & 0 & 20 \\
\hline 477178 & JETRONIC INDUSTRIES INC & 1967 & 1997 & 21.9 & 0.03 & 0 & 19 \\
\hline 594793 & MICREL INC & 1988 & 1997 & 35.9 & 3.79 & 5 & 19 \\
\hline 553649 & MSI ELECTRONICS INC & 1977 & 1997 & 1.1 & 0.11 & 0 & 17 \\
\hline 541402 & LOGIC DEVICES INC & 1976 & 1997 & 13.5 & 1.66 & 1 & 17 \\
\hline 00754E & ADVANCED PHOTONIX INC -CL A & 1985 & 1997 & 6.8 & 1.85 & 1 & 16 \\
\hline 909149 & UNIPHASE CORP & 1980 & 1997 & 32.9 & 3.06 & 3 & 16 \\
\hline 449693 & IMP INC & 1982 & 1997 & 59.8 & 7.19 & 3 & 15 \\
\hline 868532 & SUPERTEX INC & 1977 & 1997 & 31.8 & 4.43 & 0 & 14 \\
\hline 148881 & CATALYST SEMICONDUCTOR INC & 1988 & 1996 & 48.8 & 4.25 & 2 & 13 \\
\hline 928497 & VITESSE SEMICONDUCTOR CORP & 1988 & 1997 & 35.6 & 8.79 & 0 & 13 \\
\hline 254547 & DIONICS INC & 1973 & 1997 & 1.3 & 0.03 & 0 & 10 \\
\hline 007768 & AEROFLEX INC & 1974 & 1997 & 65.6 & 0.69 & 0 & 9 \\
\hline 01877H & ALLIANCE SEMICONDUCTOR CORP & 1992 & 1997 & 119.3 & 8.37 & 6 & 9 \\
\hline 594850 & MICRO LINEAR CORP & 1987 & 1997 & 41.7 & 9.21 & 3 & 9 \\
\hline 683960 & OPTI INC & 1991 & 1997 & 134.1 & 8.76 & 0 & 8 \\
\hline 404160 & HEI INC & 1977 & 1997 & 17.3 & 0.63 & 0 & 7 \\
\hline 829204 & SIMTEK CORP & 1984 & 1997 & 1.2 & 0.82 & 0 & 6 \\
\hline 595137 & MICROSEMI CORP & 1976 & 1997 & 119.2 & 0.92 & 1 & 5 \\
\hline 816629 & SEMICON INC & 1976 & 1997 & 6.7 & 0.20 & 0 & 5 \\
\hline 450909 & IBIS TECHNOLOGY INC & 1989 & 1997 & 3.2 & 1.24 & 1 & 5 \\
\hline 683815 & OPTEK TECHNOLOGY INC & 1981 & 1997 & 55.6 & 0.58 & 1 & 3 \\
\hline
\end{tabular}


Table B.2 (continued)

\begin{tabular}{|c|c|c|c|c|c|c|c|}
\hline CUSIP & Name of Firm & $\begin{array}{c}\text { First year } \\
\text { of data }\end{array}$ & $\begin{array}{c}\text { Last year } \\
\text { of data }\end{array}$ & $\begin{array}{c}\text { Sales in } \\
1994(\$ M)\end{array}$ & $\begin{array}{c}\text { R\&D in } \\
1994(\$ M)\end{array}$ & $\begin{array}{l}\text { Granted } 1994 \\
\text { Patent Apps. }\end{array}$ & $\begin{array}{c}\text { Total Patents } \\
\text { thru } 1996\end{array}$ \\
\hline $45811 \mathrm{~K}$ & INTEGRATED CIRCUIT SYSTEMS & 1985 & 1997 & 93.8 & 10.65 & 0 & 3 \\
\hline 594946 & MICROELECTRONIC PACKAGING & 1989 & 1997 & 42.4 & 1.73 & 0 & \\
\hline 237887 & DATA SYSTEMS \& SOFTWARE INC & 1973 & 1997 & 79.7 & 2.91 & 0 & 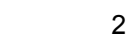 \\
\hline 553477 & MRV COMMUNICATIONS INC & 1983 & 1997 & 17.5 & 2.14 & 0 & 0 \\
\hline 747277 & QLOGIC CORP & 1991 & 1997 & 57.7 & 7.60 & 0 & 2 \\
\hline 248719 & DENSE-PAC MICROSYSTEMS INC & 1984 & 1997 & 11.5 & 0.58 & 0 & 2 \\
\hline $88554 \mathrm{~L}$ & THREE-FIVE SYSTEMS INC & 1989 & 1997 & 85.5 & 1.27 & 0 & \\
\hline 895919 & TRIDENT MICROSYSTEMS INC & 1992 & 1997 & 69.1 & 9.56 & 1 & \\
\hline 449180 & HYTEK MICROSYSTEMS INC & 1982 & 1997 & 4.2 & 0.65 & 0 & \\
\hline $68556 \mathrm{E}$ & ORBIT SEMICONDUCTOR INC & 1993 & 1995 & 43.5 & 2.34 & 0 & \\
\hline 595135 & MICROPAC INDUSTRIES INC & 1977 & 1997 & 9.4 & 0.32 & 0 & \\
\hline 816850 & SEMTECH CORP & 1975 & 1997 & 25.8 & 0.88 & 0 & \\
\hline $05548 \mathrm{E}$ & BKC SEMICONDUCTORS INC & 1991 & 1997 & 11.4 & 0.16 & 0 & \\
\hline 989601 & ZING TECHNOLOGIES INC & 1985 & 1997 & 11.5 & 0.84 & 0 & \\
\hline
\end{tabular}

Notes to table:

Sales and R\&D are in millions of 1994 dollars.

Beginning and end years are for our dataset, not for the lifetime of the firm.

Granted patents in 1994 are the patents applied for in 1994 that have been granted by 1996.

The patent total is all the patents granted to our firms that were applied for after the beginning year and granted by 1996 . 


\section{Appendix C: An Examination of Firm Effects}

A common concern in the analysis of panel data is the coefficient bias that may result from the presence of unobserved firm characteristics that are correlated with included right hand side variables. Because we are interested in examining observed differences in behavior across firms, we do allow for firm effects in our main analyses. This appendix investigates the importance of unobservable firm effects and demonstrates that unobserved differences across firms in their patenting behavior, although possibly present, do not substantially alter the estimated coefficients presented in Table 2.

To do this, we use the conditional (fixed effect) and random effects Poisson models introduced by Hausman, Hall, and Griliches (1984). ${ }^{46}$ Our sample is slightly different from the one used for the other tables because 9 smaller firms in our sample of 95 have no patents and therefore contribute nothing to the conditional estimation. Table C.1 presents the results of three estimations using the reduced sample of 86 firms: the conventional Poisson model (the same version as column (3) of Table 2), a conditional model that is consistent in the presence of unobserved firm effects that are correlated with the observed variables, and a model with uncorrelated unobserved firm effects that merely introduce a "variance components" structure to the error term.

Note first that changing the sample of firms makes very little difference to the estimates (compare column (1) to Table 2). Second, all three sets of estimates are quite similar for the coefficients that are identified (the entrant and TI dummies are not, of course). The coefficient that changes the most is that for R\&D intensity, which nearly doubles, albeit with a large standard error. As we will see later, this may reflect in part the increased role of the smaller design firms: once we allow for overall differences across firms, the influence of R\&D intensity on their patenting becomes more salient. Third, the estimated year effects are very slightly lower, but the conclusion of a doubling of patenting rates between 1986 and 1995 remains.

In columns (2) and (3) of Table 3, we present the results of two different specification tests: (a) in column (2), a test for the "ignorability" of firm effects, which is a test of whether the conditional and marginal coefficients, or equivalently, conditional and total coefficients, are equal; (b) in column (3), a (weaker) test for the presence of firm effects, which is a test of whether the conditional and marginal random effects coefficients are equal. ${ }^{47}$ That is, column (3)

\footnotetext{
${ }^{46}$ Explorations using the negative binomial model produced similar results and are not reported.

${ }^{47}$ See Hausman, Hall, and Griliches (1984) for details of the likelihood ratio versions of these tests.
} 
tests for the presence of the effects, and column (2) tests whether they are related to the right hand side variables.

We perform each of the tests in two ways: a conventional likelihood ratio test, which requires that the distributions truly be Poisson-based for consistency; and a robust Wald test based on the robust standard error estimates, which will be consistent even if the precise distributional assumption does not hold. The robust test requires only that the effects are multiplicative in form and the functional form assumption for the mean holds. That is, we need

$$
E\left[p_{i t} \mid X_{i t}, \eta_{i}\right]=\lambda_{i t}=\eta_{i} \exp \left(X_{i t} \beta+\gamma_{t}\right)
$$

where $\eta_{i}$ is the multiplicative firm-level propensity to patent.

The results of the tests indicate that unobserved differences across firms in their patenting behavior, although possibly present, do not substantially alter the estimated coefficients. In fact, using the robust versions of the tests, they are completely insignificant. Using the likelihoodbased versions, there is weak evidence for the presence of unobserved differences across firms, and somewhat stronger evidence that, if present, they affect the coefficient estimates. As a check on this conclusion, and to explore the presence of a lagged dependent variable in the relationship, we also computed the autocorrelation function of the generalized residuals from the Poisson totals estimates, and found that the largest correlation was about 0.2. Our conclusion is that, in contrast to earlier results using these kinds of data that were based on a wide range of industries, the role of firm effects is somewhat diminished when we look within a rather narrow industry definition as we do here. For this reason, the analyses contained in the body of our paper allow for observed permanent differences across firm-types, but do not include unobserved firm effects. ${ }^{48}$

\footnotetext{
${ }^{48}$ Note that a second implication of our results here is that our standard error estimates, which do not take account of the possible serial correlation within firm in the relationship, are unlikely to be seriously downward biased from this omission.
} 
Table C.1

Patenting Propensity Estimates - Firm Effects

US Semiconductor Firms 1979-1995

86 Firms (862 Observations)

\begin{tabular}{|c|c|c|c|}
\hline Variable Name & $\begin{array}{c}\text { Poisson Totals } \\
\text { (1) } \\
\end{array}$ & $\begin{array}{c}\text { Poisson Conditional (FE) } \\
(2)\end{array}$ & $\begin{array}{c}\text { Poisson Random Effects } \\
\text { (3) }\end{array}$ \\
\hline $\begin{array}{l}\text { Log R\&D per employee } \\
\text { (\$1992 1000s) }\end{array}$ & $0.161(0.176)$ & $0.294(0.173)$ & $0.294(0.140)$ \\
\hline $\begin{array}{l}\text { Dummy for no reported } \\
\text { R\&D }\end{array}$ & $-0.36(0.56)$ & $0.26(1.03)$ & $0.20(0.48)$ \\
\hline $\begin{array}{l}\text { Log firm size } \\
\text { (1000s employees) }\end{array}$ & $0.846(0.076)$ & $0.965(0.124)$ & $0.922(0.107)$ \\
\hline $\begin{array}{l}\text { Log P\&E per employee } \\
(\$ 1992 \mathrm{~K})\end{array}$ & $0.605(0.239)$ & $0.576(0.176)$ & $0.560(0.165)$ \\
\hline $\begin{array}{l}\text { Dummy for post-1982 } \\
\text { entrants }\end{array}$ & $0.508(0.301)$ & & $0.062(0.302)$ \\
\hline Dummy (Texas Instruments) & $0.796(0.284)$ & & $0.539(0.518)$ \\
\hline Intercept (1979) & $-0.134(0.53)$ & & $-1.45(0.48)$ \\
\hline Variance parameter & & & $1.49(0.24)$ \\
\hline Log Likelihood (incl. Marginals) & $-4,033.7$ & $-4,021.1$ & $-2,410.1$ \\
\hline Chi-squared ( $p$-value) & & $25.2(.000)$ & $10.3(.035)$ \\
\hline Robust Wald test ( $\mathrm{p}$-value) & & $0.87(.929)$ & $2.55(.636)$ \\
\hline
\end{tabular}

All estimates include a full set of time dummies. Heteroskedastic-consistent standard errors are shown in parentheses.

The method of estimation is maximum likelihood for the Poisson model (which is generalized ML for the exponential mean function).

The chi-squared in column (2) is a test for the presence of firm effects. The chi-squared in column (3) is a test for the randomness of these effects.

The robust Wald test tests the same hypothesis, but uses the robust standard errors.

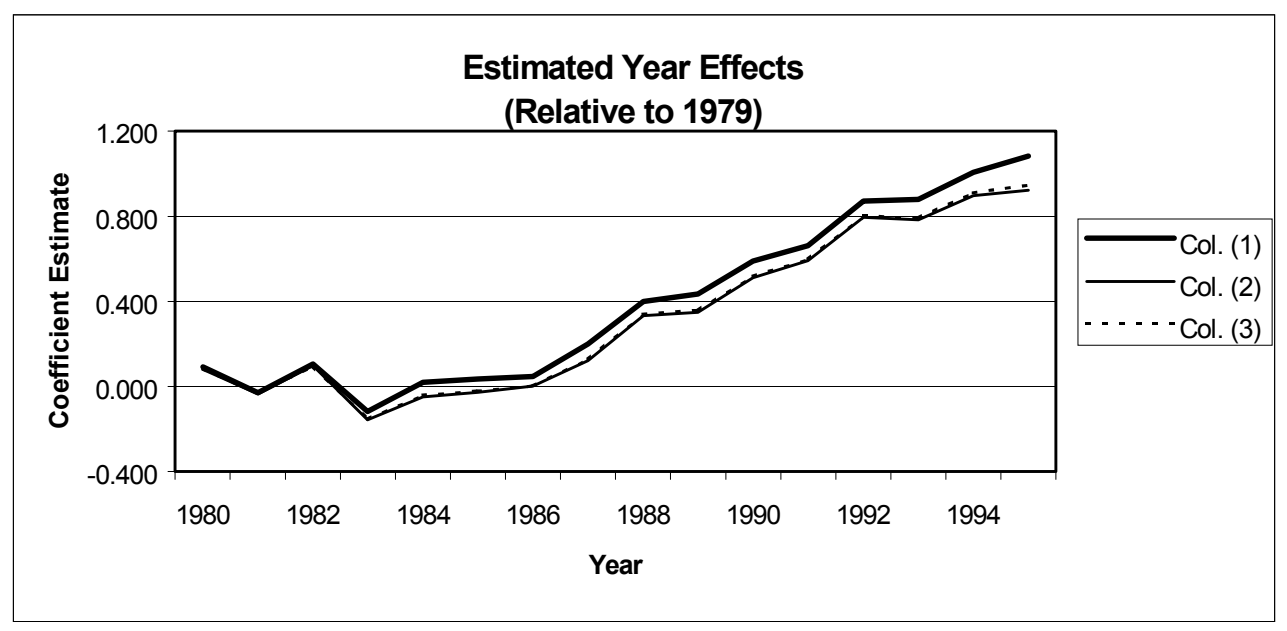

